\title{
Semantide- and Chemotaxonomy-Based Analyses of Some Problematic Phenotypic Clusters of Slowly Growing Mycobacteria, a Cooperative Study of the International Working Group on Mycobacterial Taxonomy
}

L. G. WAYNE, ${ }^{1 *}$ R. C. GOOD,${ }^{2}$ E. C. BOTTGER ${ }^{3}$ R. BUTLER, ${ }^{2}$ M. DORSCH, ${ }^{4}$ T. EZAKI, ${ }^{5}$ W. GROSS, ${ }^{6}$ V. JONAS, ${ }^{7}$ J. KILBURN, ${ }^{2}$ P. KIRSCHNER, ${ }^{3}$ M. I. KRICHEVSKY, ${ }^{8}$ M. RIDELL, ${ }^{9}$ T. M. SHINNICK, ${ }^{2}$ B. SPRINGER, ${ }^{3}$ E. STACKEBRANDT, ${ }^{4}$ I. TARNOK ${ }^{10}$ Z. TARNOK, ${ }^{10} \mathrm{H}$. TASAKA,${ }^{11} \mathrm{~V}$. VINCENT, ${ }^{12}$ N. G. WARREN, ${ }^{13}$ C. A. KNOTT, ${ }^{7}$ AND R. JOHNSON ${ }^{14}$

Department of Veterans Affairs Medical Center, Long Beach, California $90822^{1}$; Centers for Disease Control and Prevention, Atlanta, Georgia 303332; Medical School Hannover, Hannover, Germany ${ }^{3}$; University of Queensland, Brisbane, Australia ;

Gifu University School of Medicine, Gifu, Japan ${ }^{5}$; Department of Veterans Affairs Medical Center, West Haven, Connecticut 06510 ; Gen-Probe, Incorporated, San Diego, California 92121 ${ }^{7}$; Bionomics International, Rockville, Maryland 20852 ${ }^{8}$; University of Göteborg, Göteborg, Sweden ${ }^{9}$; Tuberkulose Forschungsinstitut, Borstel, Germany ${ }^{10}$; Hiroshima University School of Medicine, Hiroshima, Japan ${ }^{11}$; Institut Pasteur, Paris, France ${ }^{12}$; Association of State and Territorial Public Health Laboratory Directors, Washington, D.C. 20036 ${ }^{13}$; and Chromagen Incorporated, San Diego, California $92121^{14}$

\begin{abstract}
During previous cooperative numerical taxonomic studies of slowly growing mycobacteria, the International Working Group on Mycobacterial Taxonomy described a number of strains whose taxonomic status was ambiguous. A new study of DNA, RNA, and proteins from 66 of these organisms was performed to correlate their properties with phenotypic clustering behavior; the results of this study permitted 51 of the strains studied to be assigned to known species. The methods used to characterize the semantides included nucleotide sequencing and assessment of levels of semantide relatedness by affinity binding techniques, including whole DNA-DNA hybridization, probe hybridization, and antibody binding. There was good overall agreement between the phenotypic and chemotaxonomic clusters and the groups of organisms identified by semantide analyses. Our results supported the conclusion that we should continue to rely on polyphasic taxonomy to provide satisfactory systematic resolution of members of the genus Mycobacterium. We identified no single 16S rRNA interstrain nucleotide sequence difference value that unequivocally defined species boundaries. DNADNA hybridization remains the gold standard, but common resources are needed to permit DNA-DNA hybridization analyses to be made available to laboratories that are not prepared to use this technology. One of the large novel clusters which we studied corresponds to the recently described species Mycobacterium interjectum, a pathogen that resembles the nonpathogen Mycobacterium gordonae phenotypically. We also identified strains that appear to represent ribovars of Mycobacterium intracellulare which do not react with the commercial diagnostic probes that are currently used for identification of this species. Other branches or clusters consisted of too few strains to permit a decision about their taxonomic status to be made.
\end{abstract}

Approximately 17 years ago the International Working Group on Mycobacterial Taxonomy (IWGMT) began a cooperative open-ended study in which phenotypically unusual strains of slowly growing mycobacteria were collected on a continuing basis. These strains were distributed to participants in the open-ended study for characterization by a broad range of predominantly phenotypic tests, and at intervals the data obtained were subjected to numerical taxonomic (NT) analyses (29-32). The purpose of studying an expanding set of cultures was to characterize slowly growing mycobacterial strains that either represented uncommonly encountered species that had not been represented in previous cooperative studies $(10,25$, 28 ) or belonged to clusters of previously unrecognized taxa. These analyses yielded expanded phenotypic characterizations of members of some clusters that had not been thoroughly characterized before, such as the clusters that included the type strains of Mycobacterium simiae, Mycobacterium szulgai, Mycobacterium asiaticum, and Mycobacterium malmoense (31).

* Corresponding author. Mailing address: Tuberculosis Research Laboratory (151), VA Medical Center, 5905 East Seventh St., Long Beach, CA 90822. Phone: (310) 494-5805. Fax: (310) 494-5675.
However, some individual strains and phenotypic clusters emerged that exhibited no unequivocal affinity to any known species or appeared to be intermediate in character between two or more species (32). To determine the taxonomic status of these strains and clusters, the IWGMT began a new study in which semantide-based characterizations of the organisms were emphasized. The other purposes of this study were to determine whether consistent criteria for circumscription of species in terms of depth of branching on 16S rRNA phylogenetic trees could be identified and to evaluate the potential roles that a variety of semantide and chemotaxonomic methods can play in mycobacterial systematics. All three classes of semaritides (large, information-bearing molecules), including the primary semantide (DNA), secondary semantides (RNAs), and tertiary semantides (proteins), were examined (37). Some participants performed chemotaxonomic analyses as well. In this paper we describe the results of this polyphasic taxonomic study.

\section{MATERIALS AND METHODS}

Selection of strains. A total of 66 strains that had been placed in unidentifiable clusters or at isolated positions in the most recent analysis of data from the open-ended phenotypic study (32) were selected for the semantide characteriza- 
tion analysis. In addition, the following type strains of 19 validly described species and the invalid species "Mycobacterium paraffinicum" were also included in the analysis: M. asiaticum OES 90126 (from TMC 803; = ATCC 25276); Mycobacterium avium OES 90138 (from TMC 724; = ATCC 25291), Mycobacterium farcinogenes OES 90127 (from TMC 805; = NCTC $10955=$ ATCC 35753), Mycobacterium flavescens OES 90117 (from TMC 1541; = ATCC 14474), My cobacterium gastri OES 90136 (from TMC 1456; = ATCC 15754), Mycobacterium gordonae OES 90133 (from TMC 1324; = ATCC 14470), Mycobacterium intra cellulare OES 90135 (from TMC 1406; = ATCC 13950), Mycobacterium kansasii OES 90130 (from TMC 1204; = ATCC 12478), M. malmoense OES 90125 (from TMC 802; = ATCC 29571), Mycobacterium marinum OES 90129 (from TMC 1218; = ATCC 927), Mycobacterium nonchromogenicum OES 90118 (from TMC 1481 ; = ATCC 19530). "M. paraffinicum" OES 90139 (from ATCC 12670) Mycobacterium scrofulaceum OES 90132 (from TMC 1323; = ATCC 19981), Mycobacterium shimoidei OES 90013 (from Tsukamura 4796; = ATCC 27962) M. simiae OES 90128 (from TMC 1226; = ATCC 25275), M. szulgai OES 90134 (from TMC 1328; = NCTC 10831 = ATCC 35799), Mycobacterium terrae OES 90120 (from TMC 1450; = ATCC 15755), Mycobacterium triviale OES 90119 (from TMC 1453; = ATCC 23292), Mycobacterium tuberculosis OES 90123 (from TMC 102; = ATCC 27294), and Mycobacterium xenopi OES 90137 (from TMC $1482 ;=$ NCTC $10042=$ ATCC 19250). All of the strains were given new code numbers for this study, and the code was not revealed until all data had been received in the coordinator's office, after which no new data were accepted. The original code numbers that were assigned to these strains in the previous studies (29-32) are used in this paper to permit easy reference to the previously published information.

Participating laboratories and categories of analyses performed. The laboratories that agreed to submit data for the new study were given alphabetical designations (laboratories A through Q); laboratories $E, G, L$, and O dropped out of the study without submitting data. The data provided by the remaining 13 laboratories were divided into categories that included primary, secondary, and tertiary semantide data, as well as chemotaxonomic pattern data.

For purposes of this study, semantide-based relationships were defined as relationships that reflect the levels of sharing of specific base or amino acid sequences in primary, secondary, or tertiary semantides. Estimates of the levels of sharing, in turn, were based on the results of either direct sequence determinations or indirect assessments of levels of sequence similarity inferred from the affinities of selected nucleic acid or antibody probes for the corresponding semantides of the strains investigated. In this context we treated the data that were based on enzyme electrophoretic patterns as chemotaxonomic characteristics. Even though enzyme proteins themselves are semantides, the electrophoretic patterns could not be used to deduce actual levels of amino acid sequence sharing between strains.

For the purposes of this paper, chemotaxonomic characteristics included chromatographic patterns of various lipid components of mycobacterial cells, seroagglutination types, and electrophoretic patterns of enzymes

Primary semantide (DNA). Workers in two laboratories determined levels of DNA relatedness among strains. Workers in laboratory $J$ performed block experiments in which they determined the levels of DNA relatedness for all strain pairs made up of 57 of the strains distributed. Hybridization between nitrocellulose-bound single-stranded DNA and dissolved sulfonated single-stranded DNA was carried out at $80^{\circ} \mathrm{C}$, and this was followed by application of umbelliferone-labelled anti-sulfonated DNA antibody, which permitted the workers to determine fluorimetrically the level of DNA-DNA hybridization that occurred $(19,20)$. Because the conditions used for the fluorimetric assay are different from the conditions used for more conventional assays, the significant binding scores are greater than the value $(70 \%)$ that has been recommended for interpretation of traditional DNA-DNA hybridization assay values (26).

Workers in laboratory $Q$ estimated the levels of affinity between DNAs from the test strains and a series of whole genomic reference DNA probes derived from 23 mycobacteria. Eight of the DNA probes were from rapid growers, and only two of them, representing Mycobacterium fortuitum and $M$. flavescens, are discussed below. The remaining reference probes were derived from $M$. tuberculosis, $M$. kansasii, $M$. marinum, $M$. simiae, $M$. scrofulaceum, $M$. gordonae (two apparently unrelated reference strains, the type strain, and a clinical isolate), $M$. szulgai, $M$. avium, $M$. intracellulare, $M$. gastri, $M$. xenopi, $M$. terrae, $M$. triviale, $M$. nonchromogenicum, $M$. malmoense, $M$. asiaticum, and the recently described new species Mycobacterium interjectum (16) by using a colorimetric microplate assay (7). In this method, affinity at the species level is ascribed to the probe that yields the highest score of the panel used (arbitrarily assigned a value of $100 \%$ ), as long as the highest score exceeds the second highest score by at least $30 \%$.

Workers in laboratory $H$ performed a restriction fragment length polymorphism (RFLP) analysis of PCR-amplified DNA (11). The patterns observed were graded for similarity to patterns observed with established species or to arbitrarily coded novel patterns that exhibited little similarity to the patterns of known species. Results were expressed as percentages of similarity to the most similar reference pattern previously recognized in laboratory $\mathrm{H}$ or to a selected novel pattern, when appropriate.

Secondary semantides (RNAs). Workers in five laboratories performed tests to determine levels of 16S rRNA relatedness among strains; the data obtained in two of these laboratories were based on base sequence determinations, and the data obtained in the others were based on levels of hybridization with selected reference probes. Workers in laboratory $\mathrm{P}$ determined the actual sequences of all of the test strains in 16S rRNA hypervariable signature regions A and B, corresponding to Escherichia coli $16 \mathrm{~S}$ rRNA positions 125 to 270 and 408 to 503 , respectively, by using corresponding PCR-amplified DNA (6). In addition, the almost complete $16 \mathrm{~S}$ rRNA gene sequence (E. coli positions 38 to 1511$)$ of one strain that was selected to represent each of the newly recognized signature region patterns was also determined. Alignment positions 38 to 61 and 1426 to 1491 were omitted from the phylogenetic analysis, and the remaining sequences were used to construct a phylogenetic tree (13). Expanded partial sequences (corresponding to $E$. coli positions 38 to 321,393 to 549 , and 1128 to 1478 ) were determined for strains representing each of the signature sequences found in the closely related members of the $M$. avium $M$. intracellulare complex; all but the first 10 nucleotides of these sequences were used to generate an independent phylogenetic tree for this complex.

Workers in laboratory I determined the sequences of the $16 \mathrm{~S}$ rRNAs in the hypervariable signature region by using a 372-nucleotide PCR product corresponding to a location situated between positions 101 and 490 in the 16S rRNA Bacillus subtilis nomenclatural convention (17). The results were expressed as percentages of divergence from the most similar reference sequence previously recognized in laboratory I.

Workers in laboratory A used commercial DNA probes (Gen-Probe, San Diego, Calif.) that were complementary to selected regions of the $16 \mathrm{~S}$ rRNAs of $M$. gordonae and $M$. intracellulare in a chemiluminescent tube method $(1,8)$. Workers in laboratory $M$ used comparable probes complementary to the $16 \mathrm{~S}$ rRNAs of $M$. avium and $M$. tuberculosis. In addition to using the commercially available probes indicated above, workers in laboratory B used a number of experimental probes that are not available commercially. These probes were assigned arbitrary code numbers for interpreting data in this study.

Tertiary semantides (proteins). Workers in two laboratories determined levels of protein relatedness by using selected cross-absorbed antibodies as probes. Workers in laboratory $\mathrm{K}$ tested bacterial extracts by performing immunodiffusion tests with cross-absorbed antisera to the $\alpha$ antigens of members of the $M$. avium complex (i.e., $M$. avium and $M$. intracellulare), $M$. scrofulaceum, $M$. tuberculosis, $M$. gordonae, M. szulgai, and M. malmoense $(21,22)$.

Workers in laboratory $\mathrm{N}$ used the intrinsic enzyme dot blot technique on nitrocellulose sheets dotted with cross-absorbed antibodies to the T-catalases of $M$. asiaticum, $M$. avium, $M$. gordonae, $M$. intracellulare, " $M$. paraffinicum," $M$. kansasii, $M$. scrofulaceum, $M$. simiae, and $M$. tuberculosis (27).

Chemotaxonomic characteristics. Workers in one laboratory examined the electrophoretic patterns of enzyme proteins, and workers in two laboratories studied the chromatographic patterns of bacillary lipids.

Workers in laboratory $F$ performed a multilocus enzyme electrophoresis (MLEE) analysis of sonic extracts of the test strains (12). The enzymes detected included malate dehydrogenase, isocitrate dehydrogenase, peroxidase, glucose phosphate isomerase, aspartate aminotransferase, and adenylate kinase. The electrophoretic mobility of each enzyme was characterized as fast, medium, or slow, and the six-enzyme pattern obtained for each strain was coded in terms of the mobilities determined. Since the charges and molecular weights of the proteins determined their mobilities, the levels of sequence relatedness between pairs of enzymes derived from different strains could not be determined from these data; similarities could only be estimated in terms of "agree" or "not agree," which yielded six characteristics for the pairs of strains compared.

Workers in laboratory $\mathrm{C}$ saponified cells of the mycobacteria; then the mycolic acids were extracted and converted to $p$-bromophenacyl esters, and the extracts were subjected to high-performance liquid chromatography (HPLC). The retention times and peak heights were analyzed with a computer (2), and the patterns recognized were given arbitrarily assigned code numbers.

Workers in laboratory D examined extracts of the bacilli by thin-layer chromatography (TLC) and gas chromatography (GC) as previously described $(4,9)$ to determine the fatty acid and mycolic acid patterns for each strain. Eight different patterns were identified by TLC; these patterns were assigned uppercase letter designations. A total of 23 different GC patterns of mycobacterial lipids or their pyrolysis products were recognized by the workers in laboratory $D$, and these patterns were designated by lowercase letters. Thus, each strain in this study was characterized by a two-letter lipid pattern designation made up of an uppercase letter that designated the TLC pattern followed by a lowercase letter that designated the GC pattern.

Editing and analysis of phenotypic data. The data which were used in the phenetic NT analysis and for the feature frequency table were obtained from the previously published open-ended studies in which the same strains were used (32). Characteristics were coded according to the Rogosa-Krichevsky-Colwell scheme (14), and NT analyses were based on simple matching coefficients with sorting by unweighted average linkage $(15,23)$. The criteria and editing programs used to suppress irrelevant, redundant, and incomplete data have been described previously (32). Workers in laboratories $\mathrm{A}$ and $\mathrm{M}$ performed a few selected phenotypic tests with the recoded and distributed strains used in this study as a check on the distribution system, but the resulting data were not included in the full NT analysis.

A table of phenotypic feature frequencies was generated for sets of strains that were grouped for this purpose according to their levels of apparent phylogenetic relatedness, as inferred from the tree that was based on their 16S rRNA sequences rather than their positions in the phenotypic NT matrix described above. 


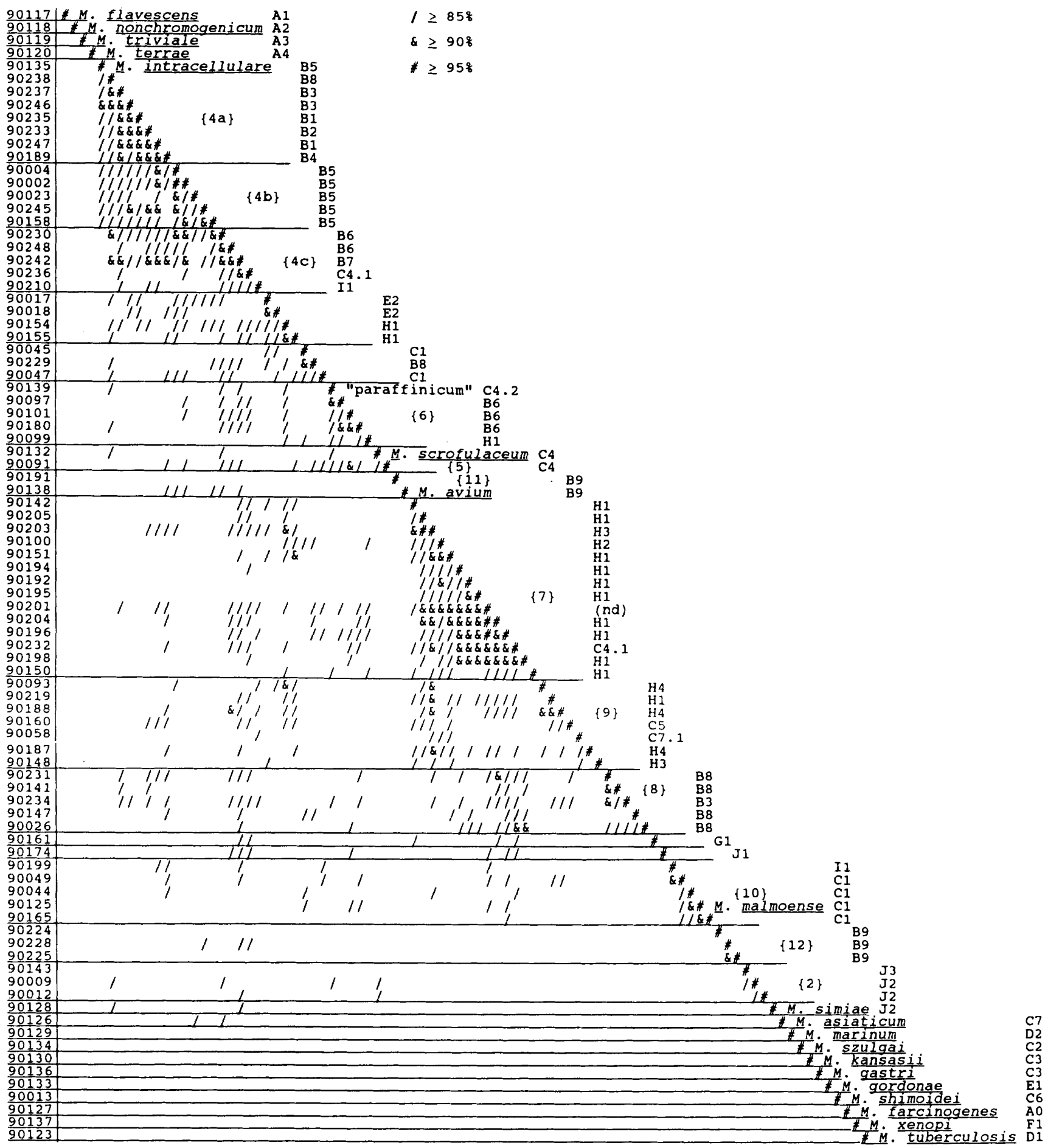

FIG. 1. Phenetic NT diagram for the strains used in this study. A name following a strain designation indicates that the culture used was derived from the type strain of the species named. The letter-number designations indicate the branches on the 16S rRNA phylogenetic trees (Fig. 2 and 3 ) that are occupied by the strains. The designations in braces indicate the phenetic clusters into which the strains fell in a previous phenotypic study (32). (nd), not determined.

The result for each strain on the feature frequency table was the modal score (i.e., the result obtained for the strain in the majority of the laboratories that performed the test) (34).

\section{RESULTS}

The phenetic NT diagram in Fig. 1 was derived from the data used to prepare a diagram in a previous study. However, only data for strains that were distributed for examination in this study were used for the diagram in Fig. 1. The suppression of the phenotypic data for strains that were not redistributed led to some transposition of strains and even clusters on the new diagram. To the extent possible, the cluster numbers on the phenetic diagram in Fig. 1 correspond to the cluster numbers used in the previous cooperative study (32). The strains 


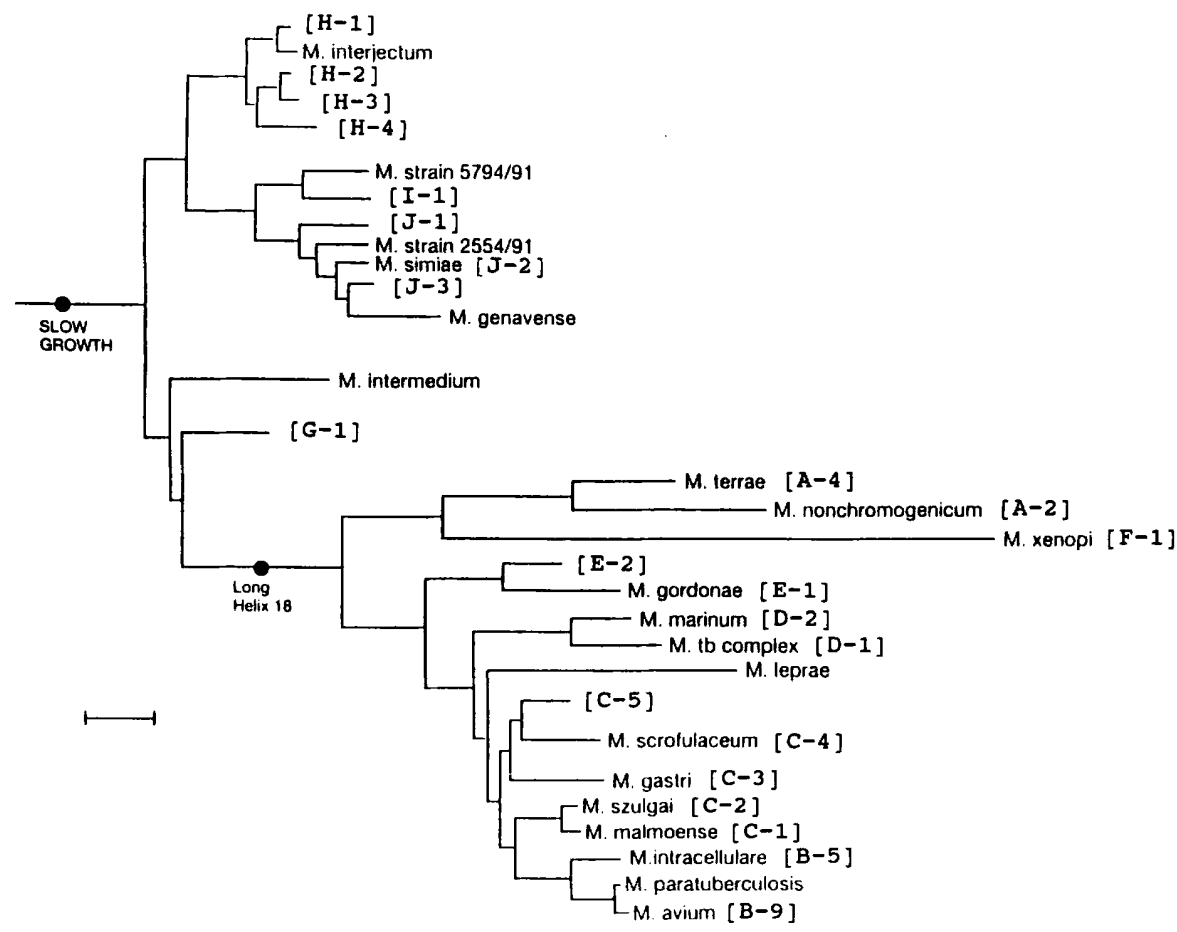

FIG. 2. Phylogenetic tree for slowly growing mycobacteria based on extended nucleotide sequences of $16 \mathrm{~S}$ rRNAs determined in laboratory P. The designations in brackets are the designations assigned to the signature region sequence groups (branches) identified in Tables 2 and 3 . When a branch included the type strain of a known species, the branch designation and the species name are given. Five species (Mycobacterium paratuberculosis [synonym, $M$. avium subsp. paratuberculosis], Mycobacterium leprae, $M$. interjectum, $M$. genavense, and $M$. intermedium) were not represented by type strains in the cultures distributed for this study. Similarly, Mycobacterium sp. strain 5794/91 (M. strain 5794/91) and Mycobacterium sp. strain 2554/91 (M. strain 2554/91) were strains in the laboratory P collection but were not among the strains distributed for this study. Bar = difference of 10 nucleotides between sequences. Nocardia asteroides was the outgroup used. M. tb complex, Mycobacterium tuberculosis complex.

distributed for this study included cultures that were derived from the type strains of 19 validly described species and one invalid species of mycobacteria; these cultures are identified by their species names in Fig. 1. The type strains of 13 species $(M$. flavescens, $M$. nonchromogenicum, $M$. triviale, $M$. terrae, $M$. marinum, $M$. szulgai, $M$. kansasii, $M$. gastri, $M$. gordonae, $M$. shimoidei, $M$. farcinogenes, $M$. xenopi, and $M$. tuberculosis) exhibited phenetic matching scores of less than $85 \%$ with all of the test strains used in this study. The remaining type strains exhibited phenetic matching scores of more than $85 \%$ with at least one other culture in the study set.

RNA studies. When the slowly growing test strains were examined in laboratory $\mathrm{P}, 29$ different nucleotide sequence patterns were observed in 146-nucleotide signature region $A$ of the 16S rRNA, and 15 patterns were observed in 96-nucleotide signature region $\mathrm{B}$. (Two strains in the study were rapid growers and were excluded from further study.) The sequences of some of the strains were identical in region $\mathrm{A}$ but different in region $\mathrm{B}$, and the converse was also true.

One strain that was representative of each of the composite nucleotide sequence patterns (i.e., the patterns in regions $\mathrm{A}$ and B combined) was selected for an expanded sequence determination study (as described in Materials and Methods), and the resulting data were used to generate phylogenetic trees based on the patterns of most of the slow growers (Fig. 2) and of a subset that included members of the $M$. avium- $M$. intracellulare complex (Fig. 3). Two strains that represented the type strains of two rapidly growing species, $M$. flavescens and M. farcinogenes, were not included on these phylogenetic trees. The European Molecular Biology Laboratory accession numbers of the 16S rRNA sequences of most of the type strains used in this study have been described previously by Rogall et al. (13), Springer et al. (16), and Böddinghaus et al. (1a), and the signature sequence of $M$. asiaticum has been described by Meir et al. (9a). New sequences determined in this study are listed in Table 1. The assignment of designations to strains or strain clusters on the phylogenetic trees was arbitrary and was based on using the same letter for occupants of a major limb containing closely allied strains or clusters, followed by numbers to distinguish between groups containing the closely related taxa (branches) on each limb. Also included on these trees were branches corresponding to previously established nucleotide sequence patterns of known species and unnamed branches, representatives of which were not included in this study. Expanded sequence data for strains that were assigned to branches C-4.1 and C- 4.2 on the basis of their signature region patterns were not included in the Hamming distance tables or phylogenetic trees that were submitted as such to the study coordinator. However, workers in the submitting laboratory indicated that strain IWGMT 90139, representing branch $C-4.2$, corresponded to " $M$. paraffinicum" and noted that the complete sequences of the two strains on branch C-4.1 differed at only two nucleotides from the sequence of $M$. scrofulaceum.

In general, there was good agreement between the positions of strains on the phenetic NT diagram and the branch designations of the organisms on the 16S rRNA phylogenetic trees (Fig. 1). With only one exception (strain IWGMT 90238), the first 13 strains in clusters $4 \mathrm{a}$ and $4 \mathrm{~b}$ on the phenetic NT diagram belonged on one of the $16 \mathrm{~S}$ rRNA branches designated B-1 through B-5, which included the type strain of $M$. intracellulare. The strains on 16S rRNA branch B-6 were distributed in 


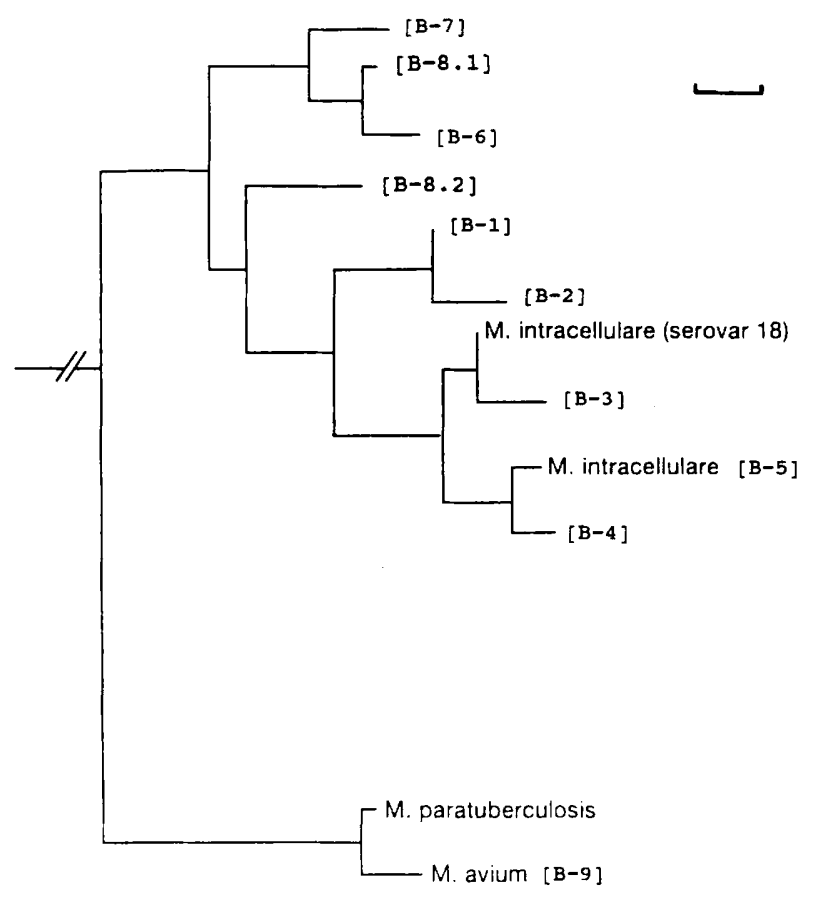

FIG. 3. Phylogenetic tree for members of the $M$. avium complex based on extended nucleotide sequences of $16 \mathrm{~S}$ rRNAs determined in laboratory $\mathrm{P}$. The designations in brackets are the designations assigned to the signature region sequence groups (branches) identified in Tables 2 and 3 . When a branch included the type strain of a known species, the branch designation and the species name are given. $M$. paratuberculosis (synonym, $M$. avium subsp. paratuberculosis) was not represented by a type strain in the cultures that were distributed for this study. The short sequences in the signature regions of members of branches B-8.1 and B-8.2 were identical (see the discussion concerning these strains in the text). Bar $=$ difference of one nucleotide between sequences. Nocardia asteroides was the outgroup used.

phenetic clusters $4 \mathrm{c}$ and 6 , but there was some intercluster affinity at matching scores of $\geq 85 \%$ between some strains belonging to these two clusters; cluster 6 also contained the type strain of the nonvalid species " $M$. paraffinicum," although on the 16S rRNA tree this strain was clearly distinguished from other strains belonging to this cluster. The strains on $16 \mathrm{~S}$

TABLE 1. European Molecular Biology Laboratory accession numbers of new 16S rRNA sequences of strains representing new branches recognized in this study

\begin{tabular}{lcc}
\hline Branch & \multicolumn{1}{c}{ Strain } & EMBL accession no. \\
\hline B-1 & IWGMT 90247 \\
B-2 & IWGMT 90233 & X88917 \\
B-3 & IWGMT 90237 & X88918 \\
B-7 & IWGMT 90242 & X88920 \\
B-8.1 & IWGMT 90238 & X88921 \\
B-8.2 & IWGMT 90147 & X88916 \\
C-4.1 & IWGMT 90236 & X88912 \\
C-5 & IWGMT 90160 & X88911 \\
E-2 & IWGMT 90018 & X88907 \\
G-1 & IWGMT 90161 & X88914 \\
H-2 & IWGMT 90100 & X88915 \\
H-3 & IWGMT 90203 & X88909 \\
H-4 & IWGMT 90093 & X88910 \\
I-1 & IWGMT 90210 & X88913 \\
J-1 & IWGMT 90174 & X88908 \\
J-3 & IWGMT 90143 & X88906 \\
\hline
\end{tabular}

${ }^{a}$ EMBL, European Molecular Biology Laboratory.
rRNA branch B-8 appeared in phenetic cluster $4 \mathrm{a}$, an unlabelled cluster above cluster 6 , and cluster 8 ; there was little phenetic affinity between the branch B-8 strains in cluster 8 and the strains in the other clusters. The branch B-9 strains of $M$. avium in cluster 11 exhibited little phenetic affinity with their counterparts in cluster 12, although, as discussed below, all of these strains did appear to be members of the same species. Large phenetic cluster 7 comprised predominantly branch $\mathrm{H}-1$ strains; individual branch $\mathrm{H}-1$ strains also appeared in the unlabelled cluster just below cluster $4 c$, cluster 6 , and cluster 9. In each case the matching scores between these outlying branch $\mathrm{H}-1$ strains and some cluster 7 strains were high enough that the branch $\mathrm{H}-1$ strains could reasonably be considered members of cluster 7. Strains belonging to $16 \mathrm{~S}$ rRNA branches $\mathrm{H}-2, \mathrm{H}-3$, and $\mathrm{H}-4$ appeared in phenetic clusters 7 and 9.

There are no universally applicable criteria for deciding how many base deletions and/or substitutions in 16S rRNA sequences are sufficient to justify establishment of a new species (18). A useful approach for identifying natural evolutionary discontinuities is to plot frequency distributions of matching or distance scores and identify null points in these distributions that appear to represent natural taxon borders for a given group of organisms (24). This was done with the two sets of $16 \mathrm{~S}$ rRNA Hamming distances used to generate Fig. 2 and 3. Hamming distances were calculated by determining the number of 16S rRNA nucleotide differences between two strains when substitutions, deletions, or additions were weighted equally (13); the trees were constructed by the neighborliness method (4a). When a compressed histogram of the Hamming distances for the large $(1,384$-nucleotide) sequences of a broad range of species was drawn (Fig. 4A), a major bimodal distribution was observed. This distribution reflected the two major limbs on the phylogenetic tree (Fig. 2), i.e., the limbs containing strains with and without long helix 18 . A second histogram was prepared by using the same data, and this second histogram was limited to an expanded-scale presentation of the Hamming distances that fell in the range between 1 and 20 nucleotides (Fig. 4B). Although there were fewer datum points, there was evidence of discontinuities after scores representing 3,5,9, and 17 substitutions. A triangular matrix was prepared by using the Hamming distances for the strains in this study for which complete sequences had been determined and symbols that corresponded to the Hamming distance score clusters identified in Fig. 4B. (It should be noted that the type strains of the new species $M$. interjectum, Mycobacterium intermedium, and Mycobacterium genavense were not included in the set of strains distributed for this study, but the 16S rRNA sequences of these strains are now available and were incorporated into this analysis of data.) The triangular matrix (Fig. 4C) showed that most Hamming distances between pairs of type strains of established species were 10 or greater. A striking exception was the high level of similarity between $M$. malmoense and $M$. szulgai.

Because of special interest in the relationships among members of the $M$. avium- $M$. intracellulare complex, a separate analysis was performed with the strains that exhibited the highest levels of similarity to the type strains of $M$. avium and $M$. intracellulare. The 782-nucleotide sequence data were used in this analysis. The histogram of the Hamming distances obtained for this select group of strains exhibited a tetramodal distribution over a narrow range of values (Fig. 5A). The null points were used to select symbols for a triangular matrix (Fig. 5B). The strains representing branches B-1 through B-4 clustered with the type strain of $M$. intracellulare (branch B-5), with average Hamming distances less than 7 , and all of these strains exhibited Hamming distances of 12 or more with $M$. avium. 

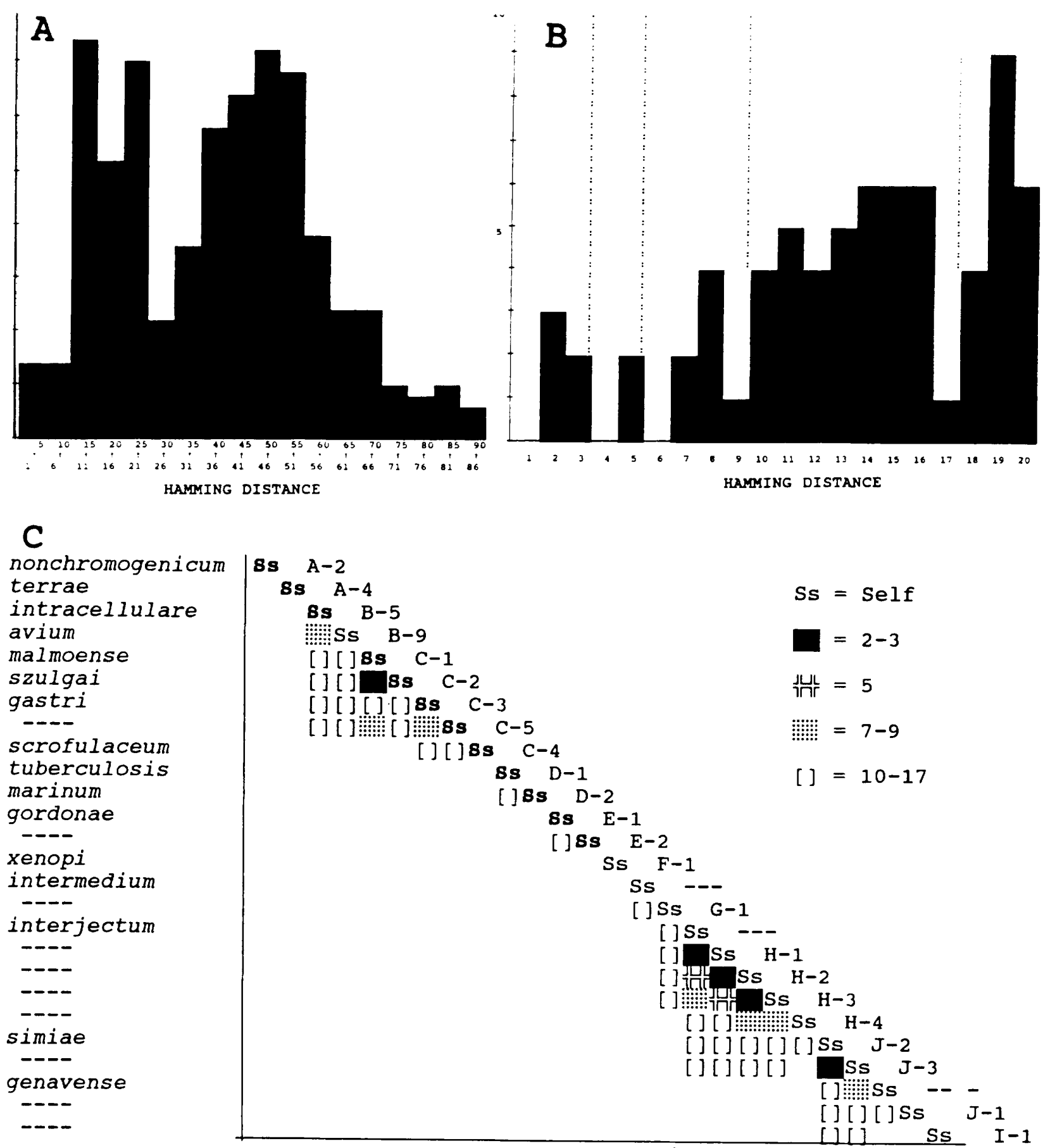

FIG. 4. Distribution of Hamming distances (expressed as numbers of nucleotide substitutions, insertions, and/or deletions) between strain pairs consisting of representatives of most of the branches on the $16 \mathrm{~S}$ rRNA phylogenetic tree for slowly growing mycobacteria (Fig. 2). (A) Composite frequency distribution of Hamming distances over the entire range observed. (B) Expanded composite frequency distribution of Hamming distances over a narrow range of Hamming distances (between 2 and 20 nucleotide differences). (C) Clustering of branches based on the Hamming distances of branch pairs.

Strains on branches B-6, B-7, and B-8 formed a cluster whose average internal distance was 6 or less and whose average distances from the type strains of $M$. avium and $M$. intracellulare were 7 or more.

Workers in laboratory I recorded the 16S rRNA signature sequence distances in terms of percentages of divergence from the corresponding sequence of the most similar reference organism. Levels of divergence of $\leq 0.5 \%$ were considered incon- sequential, and the actual levels of divergence are shown in Table 2 only for the reference sequences that exhibited levels of divergence greater than $0.5 \%$.

The lower threshold for positive reactions with the commercially available DNA/RNA probes used in laboratories A and $M$ was $3 \times 10^{4}$ relative light units, and $1 \times 10^{4}$ relative light units was the unequivocal upper threshold for negative reactions. The values obtained in most of the positive reactions 


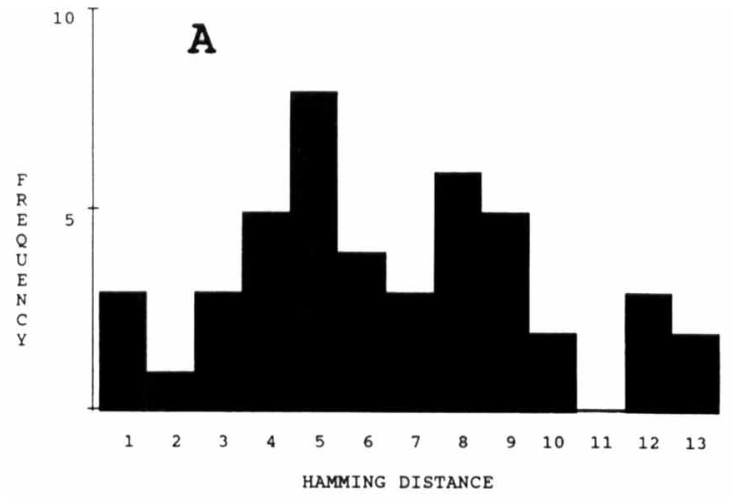

B

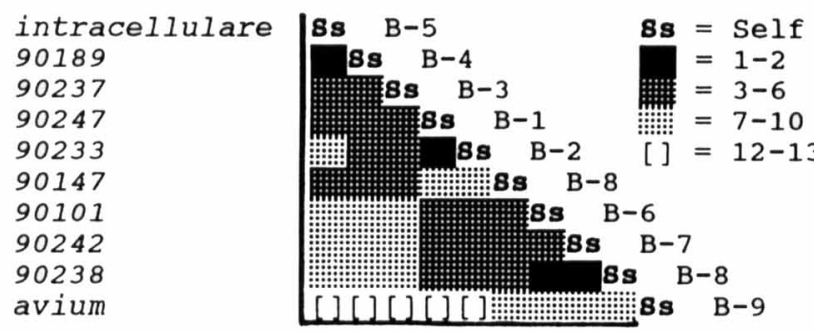

FIG. 5. Distribution of Hamming distances between strain pairs consisting of representatives of branches B-1 through B-9 on the 16S rRNA phylogenetic tree for the $M$. avium-M. intracellulare complex (Fig. 3). (A) Composite frequency distribution of Hamming distances over the entire range observed. (B) Clustering of branches based on Hamming distances of branch pairs.

observed with these probes were significantly more than of $10^{5}$ relative light units. However, in three reactions the values were between $3 \times 10^{4}$ and $10^{5}$ relative light units and these reactions were considered questionable (Table 2). All of the strains on branches B-4 and B-5, including the type strain of $M$. intracellulare, gave positive reactions with the commercial probe for $M$. intracellulare, but none of the strains on branches B-1 through B-3 or B-6 through B-9 gave positive reactions with this probe; one strain each on branches $\mathrm{C}-1$ and $\mathrm{C}-3$ reacted with this probe (the false-positive reaction of $M$. kansasii observed in laboratory $\mathrm{A}$ is unexplained and may reflect a labelling error), and two other strains, both members of branch I-1, gave questionable results. All of the strains on branch B-9, which included the type strain of $M$. avium, reacted with the commercial probe for $M$. avium, as did the strain on branch $\mathrm{J}-1$.

The strains that reacted with any of the novel experimental probes used in laboratory $B$ tended to react with more than one probe, but several clusters exhibited internal consistency in the pattern of probes with which they reacted. Of some interest is the observation that probe $\mathrm{D}$, which appeared to exhibit remarkable sensitivity and specificity for the strains on branch $\mathrm{H}-1$ (Table 2), was originally developed for possible use in identification of Mycobacterium haemophilum, a species that was not included in this study.

DNA studies. An $N \times N$ triangle diagram was generated for the strain pair DNA-DNA hybridization scores obtained for 57 of the distributed strains in laboratory J (Fig. 6). The sequence in which the taxa appear in Fig. 6 was determined arbitrarily on the basis of their 16S rRNA signature sequence codes to help visualize the levels of DNA-DNA relatedness in the branches.
As noted above, the procedure used to determine levels of DNA-DNA hybridization in laboratory $\mathbf{J}$ yielded higher values than the values obtained with other, more traditional methods. In order to gain some insight into appropriate species cutoff levels for DNA hybridization data when this technique is used, the data obtained in laboratory $\mathrm{J}$ from 91 strain pair hybridizations that resulted from cross-testing the DNAs of the type strains of 14 species represented in this study were segregated and used in an independent analysis. The frequency distribution of the resulting cross-hybridization data was plotted, and it was found that the data exhibited a tetramodal distribution and that the maximum interspecies value for members of the known species was $81 \%$ (Fig. 7A). On the basis of this distribution, a different symbol was assigned to each of the three highest ranges of interspecies hybridization values ( 46 to 65,66 to 80 , and $81 \%$ ) when a triangular NT diagram for the 14 type strains was constructed (Fig. 7B). On the basis of these values and the DNA hybridization NT diagram for all of the strains used in the study (Fig. 6), it appeared that members of different species exhibited hybridization values of less than $85 \%$ and that hybridization values of more than $85 \%$ meant that organisms belonged to the same species when this technique was used. Furthermore, there also appeared to be some correlation between lower DNA-DNA hybridization values and distribution on the major limbs of the 16S rRNA phylogenetic tree.

The type strains of $M$. flavescens, $M$. nonchromogenicum, $M$. triviale, $M$. terrae, $M$. gastri, $M$. tuberculosis, and $M$. xenopi exhibited less than $81 \%$ hybridization with each other and with the other 50 strains examined (Fig. 6). With strains on branches B-1 through B-5, including the type strain of $M$. intracellulare, hybridization values for strain pairs that were greater than $85 \%$ were common; however, strain IWGMT 90234 appeared to be aberrant, because the levels of hybridization between this strain and all other strains on these five branches were less than $81 \%$. The three strains on branch B-6 exhibited high levels of relatedness to each other, and in some comparisons with members of other clusters the levels of relatedness were greater than $81 \%$. The two branch B-8 strains that were tested exhibited a low level of affinity with each other, but strain IWGMT 90141 DNA did exhibit moderate to high levels of affinity with DNAs of some strains on branches B-3, B-4, and B-6, as well as B-9, which included the type strain of $M$. avium. There was some ambiguity in the interpretation of some high values that were scattered throughout the diagram; these values did not appear to represent clustering behavior, but rather they were isoalted values which may have reflected some technical variation in the test itself. $M$. malmoense was represented by three closely related strains in cluster $\mathrm{C}-1$, which also exhibited a few scattered high values on the diagram. For purposes of tabulation of the data obtained in laboratory J (Table 2), a strain was placed in a species or cluster if its median level of hybridization with members of the cluster was greater than $85 \%$. In some cases this led to multiple ascriptions for a strain.

Workers in laboratory Q probed 86 of the distributed strains with DNAs from the reference species and were able to place 67 of these strains in 1 of 18 species. The remaining 19 strains could not be identified with any of the probes (Table 2).

Workers in laboratory $\mathrm{H}$ reported that the DNA RFLP patterns of strains from most of the branches exhibited matching scores at levels of $83 \%$ or higher to patterns that had already been recognized in known species (Table 2). Almost all members of branches B-1 through B-5, including the type strain of $M$. intracellulare, exhibited high levels of similarity with the INT-1 pattern. The patterns of strains on branches B-6 and B-7, as well as the patterns of strains on branches C-4 
TABLE 2. Semantide characterization of mycobacterial strains ${ }^{a}$

\begin{tabular}{|c|c|c|c|c|c|c|c|c|c|c|}
\hline \multirow[b]{2}{*}{ Strain } & \multirow{2}{*}{ Species $^{b}$} & \multicolumn{2}{|c|}{$\begin{array}{l}\text { DNA-DNA homology } \\
\text { groups }\end{array}$} & \multirow{2}{*}{$\begin{array}{l}\text { DNA RFLP } \\
\text { pattern }^{e}\end{array}$} & \multirow{2}{*}{$\begin{array}{c}\text { 16S } \\
\text { rRNA } \\
\text { sequence } \\
\text { branch }^{f}\end{array}$} & \multirow{2}{*}{$\begin{array}{l}\text { 16S rRNA sequence } \\
\text { group }^{g}\end{array}$} & \multicolumn{2}{|c|}{$\begin{array}{l}\text { 16S rRNA probe } \\
\text { groups }\end{array}$} & \multicolumn{2}{|c|}{$\begin{array}{l}\text { Protein analysis } \\
\text { groups }\end{array}$} \\
\hline & & $\begin{array}{c}\mathrm{N} \times \mathrm{N} \\
\text { analysis }\end{array}$ & $\begin{array}{c}\text { Probe } \\
\text { analysis }\end{array}$ & & & & $\begin{array}{l}\text { Standard } \\
\text { probes }^{h}\end{array}$ & $\begin{array}{c}\text { New } \\
\text { probe }^{i}\end{array}$ & $\begin{array}{c}\alpha \\
\text { Antigen } \\
\text { analysis' }\end{array}$ & $\begin{array}{l}\text { T-catalase } \\
\text { analysis }\end{array}$ \\
\hline IWGMT 90127 & M. farcinogenes & & FOR & FOR2-100 & $A-0$ & & $\mathrm{u}^{\prime}$ & & $\mathrm{u}$ & \\
\hline IWGMT 90117 & M. flavescens & FLA & & UNK5 & A-1 & TRI:6.5 & u & & & \\
\hline IWGMT 90118 & M. nonchromogenicum & NON & NON & FOR2-100 & A-2 & NON & u & & u & $(\mathrm{t}-)^{m}$ \\
\hline IWGMT 90119 & M. triviale & TRI & TRI & noamp ${ }^{n}$ & $A-3$ & TRI & $\mathrm{u}$ & & $\mathrm{u}$ & $(t-)$ \\
\hline IWGMT 90120 & M. terrae & TER & TER & UNK2 & A-4 & TER & $\mathrm{u}$ & & u & $(t-)$ \\
\hline IWGMT 90235 & & & INT & INT1-95 & B-1 & & $\mathrm{u}$ & $\mathrm{MAC} / \mathrm{A} / \mathrm{B}$ & MAC & u \\
\hline IWGMT 90247 & & INT/H-1 & INT & INT1-100 & B-1 & INT & $\mathrm{u}$ & $\mathrm{MAC} / \mathrm{A} / \mathrm{B}$ & MAC & $\mathrm{u}$ \\
\hline IWGMT 90233 & & INT & INT & INT1-95 & B-2 & INT & $\mathrm{u}$ & $\mathrm{MAC} / \mathrm{A} / \mathrm{B}$ & MAC & $\mathrm{u}$ \\
\hline IWGMT 90237 & & INT & INT & INT1-100 & B-3 & INT & u & $\mathrm{MAC} / \mathrm{A} / \mathrm{B}$ & MAC & u \\
\hline IWGMT 90246 & & & INT & INT1-95 & B-3 & & $\mathrm{u}$ & $\mathrm{MAC} / \mathrm{A} / \mathrm{B}$ & MAC & u \\
\hline IWGMT 90234 & & $\mathrm{ncl}^{o}$ & INT & UNK4 & B-3 & INT & u & $\mathrm{MAC} / \mathrm{A} / \mathrm{B}$ & MAC & u \\
\hline IWGMT 90189 & & INT & INT & INT2-100 & B-4 & INTv12 & INT & & MAC & INT \\
\hline IWGMT 90135 & M. intracellulare & INT & INT & INT1-100 & B-5 & INTv12 & INT & & MAC & INT \\
\hline IWGMT 90004 & & & INT & INT1-100 & B-5 & & INT & $\mathrm{MAC} / \mathrm{A} / \mathrm{B}$ & MAC & INT \\
\hline IWGMT 90002 & & & INT & INT3-77 & B-5 & & INT & $\mathrm{MAC} / \mathrm{A} / \mathrm{B}$ & MAC & INT \\
\hline IWGMT 90023 & & INT & INT & INT1-100 & B-5 & INT & INT & $\mathrm{MAC} / \mathrm{B}$ & MAC & u \\
\hline IWGMT 90245 & & & INT & INT1-100 & B-5 & & INT & $\mathrm{MAC} / \mathrm{A} / \mathrm{B}$ & MAC & INT \\
\hline IWGMT 90158 & & INT & $\mathrm{u}$ & INT1-100 & B-5 & INTv12 & INT & $\mathrm{MAC} / \mathrm{A} / \mathrm{B}$ & MAC & INT \\
\hline IWGMT 90230 & & & INT & SCR1-83 & B-6 & & $\mathrm{u}$ & & $\mathrm{SCR}$ & $\mathrm{u}$ \\
\hline IWGMT 90248 & & INT? & INT & XEN3-88 & B-6 & INTv7 & $\mathrm{u}$ & $\mathrm{MAC} / \mathrm{A} / \mathrm{B}$ & SCR & $\mathrm{u}$ \\
\hline IWGMT 90097 & & INT? & INT & SCR1-83 & B-6 & INTv7 & u & A & SCR & $\mathrm{u}$ \\
\hline IWGMT 90101 & & INT? & INT & SCR2-83 & B-6 & INTv7/18:0.5-0.9 & $\mathrm{u}$ & A & SCR & $\mathbf{u}$ \\
\hline IWGMT 90180 & & & INT & SCR1-82 & B-6 & & $\mathrm{u}$ & $\mathrm{MAC} / \mathrm{A}$ & SCR & u \\
\hline IWGMT 90242 & & & INT & XEN3-88 & B-7 & & u & $\mathrm{MAC} / \mathrm{B}$ & MAC & $\mathrm{u}$ \\
\hline IWGMT 90238 & & & INT & XEN3-88 & B-8 & & $\mathrm{u}$ & $\mathrm{MAC} / \mathrm{B}$ & $\mathrm{SCR}$ & $\mathrm{u}$ \\
\hline IWGMT 90231 & & & INT & SCR1-83 & B-8 & & u & $\mathrm{MAC} / \mathrm{B}$ & SCR & AVI? \\
\hline IWGMT 90141 & & INT & INT & SCR3-88 & B-8 & INT & $\mathrm{u}$ & $\mathrm{MAC} / \mathrm{A} / \mathrm{B}$ & $\mathrm{u}$ & u \\
\hline IWGMT 90026 & & & INT & SCR1-83 & B-8 & & $\mathrm{u}$ & & SCR & $\mathrm{u}$ \\
\hline IWGMT 90147 & & $\mathrm{ncl}$ & INT & SCR3-83 & B-8 & INTv7/18:0.5-0.9 & $\mathrm{u}$ & $\mathrm{MAC} / \mathrm{A} / \mathrm{B}$ & $\mathrm{u}$ & $\mathrm{u}$ \\
\hline IWGMT 90229 & & & INT & XEN3-88 & B-8 & & $\mathrm{u}$ & MAC & SCR & AVI \\
\hline IWGMT 90191 & & AVI & AVI & UNK6b & B-9 & INTv4/PRT:1.4-1.8 & AVI & & MAC & AVI \\
\hline IWGMT 90138 & M. avium & AVI & AVI & AVI- 83 & B-9 & INTv4/PRT:0.5 & AVI & & MAC & AVI \\
\hline IWGMT 90224 & & & AVI & AVI-97 & B-9 & & AVI & & MAC & AVI \\
\hline IWGMT 90228 & & & AVI & AVI-83 & B-9 & & AVI & & MAC & AVI \\
\hline IWGMT 90225 & & & AVI & AVI-83 & B-9 & & AVI & & MAC & AVI \\
\hline IWGMT 90045 & & & $\mathrm{u}$ & MAL-100 & C-1 & & $\mathrm{u}$ & & MAL & \\
\hline IWGMT 90047 & & & $\mathrm{u}$ & MAL-100 & $\mathrm{C}-1$ & & $\mathrm{u}$ & & MAL & SIM \\
\hline IWGMT 90049 & & MAL & MAL & MAL-100 & $\mathrm{C}-1$ & SZU/MAL: $\leq 0.6$ & $\mathrm{u}$ & & MAL & $\mathrm{u}$ \\
\hline IWGMT 90044 & & & $\mathbf{u}$ & MAL-90 & $C-1$ & & INT & $\mathrm{u}$ & MAL & $\mathrm{u}$ \\
\hline IWGMT 90125 & M. malmoense & MAL & MAL & MAL-90 & $C-1$ & SZU/MAL: $\leq 0.6$ & $\mathrm{u}$ & & MAL & $\mathrm{u}$ \\
\hline IWGMT 90165 & & MAL & MAL & MAL-100 & C-1 & SZU/MAL: $\leq 0.6$ & $\mathrm{u}$ & & MAL & $\mathrm{u}$ \\
\hline IWGMT 90134 & M. szulgai & & SZU & SZU-90 & $\mathrm{C}-2$ & SZU/MAL & u & & SZU & $\mathrm{u}$ \\
\hline IWGMT 90130 & M. kansasii & & KAN & KAN1-100 & C-3 & & INT & $\mathrm{KAN} / \mathrm{C}$ & KAN & INT/KAN \\
\hline IWGMT 90136 & M. gastri & GAS & GAS & KAN2-90 & $C-3$ & KAN & $\mathrm{u}$ & $\mathrm{A} / \mathrm{C}$ & KAN & KAN \\
\hline IWGMT 90132 & M. scrofulaceum & SCR & SCR & SCR2-100 & C-4 & SCR & $\mathrm{u}$ & $\mathrm{A} / \mathrm{C}$ & SCR & SCR \\
\hline IWGMT 90091 & & SCR/INT & SCR & SCR2-100 & C-4 & SCR & $\mathrm{u}$ & $\mathrm{A} / \mathrm{C}$ & SCR & $\mathrm{u}$ \\
\hline IWGMT 90236 & & INT? & $\mathrm{u}$ & XEN3-100 & C-4.1 & SCR: $0.3-0.6$ & u & $\mathrm{A} / \mathrm{C}$ & $\mathrm{u}$ & $(\mathrm{t}-)$ \\
\hline IWGMT 90232 & & PRF? & $\mathrm{u}$ & UNK3c & C-4.1 & & $\mathrm{u}$ & $\mathrm{A} / \mathrm{C}$ & MAC & $\mathrm{u}$ \\
\hline IWGMT 90139 & "M. paraffinicum" & PRF & SCR & SCR1-95 & C- 4.2 & SCR:1.1 & $\mathrm{u}$ & $\mathrm{A} / \mathrm{C}$ & PRF & PRF \\
\hline IWGMT 90160 & & & SCR & SCR2-72 & C-5 & & $\mathrm{u}$ & $\mathrm{A} / \mathrm{C}$ & SCR & \\
\hline IWGMT 90013 & M. shimoidei & & $\mathbf{u}$ & SHI-100 & C- 6 & & u & & u & $\mathrm{u}$ \\
\hline IWGMT 90126 & M. asiaticum & ASI & ASI & ASI-100 & $\mathrm{C}-7$ & ASI & $\mathrm{u}$ & & $\mathrm{u}$ & ASI \\
\hline IWGMT 90058 & & & $\mathrm{u}$ & ASI-92 & C-7.1 & & GOR? & $\mathrm{u}$ & GOR & ASI \\
\hline IWGMT 90123 & M. tuberculosis & TUB & TUB & TUB & D-1 & TUB & TUB & & TUB & TUB \\
\hline IWGMT 90129 & M. marinum & & MAR & MAR1-88 & D-2 & & $\mathrm{u}$ & & MAR & \\
\hline IWGMT 90133 & M. gordonae & & GOR & GOR-100 & E-1 & & GOR & & GOR & GOR \\
\hline IWGMT 90017 & & & $\mathrm{u}$ & INT3-72 & $\mathrm{E}-2$ & & GOR & & GOR & ASI \\
\hline IWGMT 90018 & & & GOR & INT3-72 & E-2 & & $\mathrm{u}$ & & GOR & ASI \\
\hline IWGMT 90137 & M. xenopi & XEN & XEN & XEN1-100 & $F-1$ & XEN:1.0 & u & & XEN & $\mathrm{u}$ \\
\hline IWGMT 90161 & & MAL? & $\mathrm{u}$ & INT2-86 & G-1 & SIM:1.4 & u & & MAC & $\mathrm{u}$ \\
\hline IWGMT 90151 & & $\mathrm{H}-1$ & IJC & UNK1-100 & $\mathrm{H}-1$ & SIM & $\mathrm{u}$ & D & MAL & $\mathrm{u}$ \\
\hline IWGMT 90154 & & H-1 & IJC & UNK3a-T & H-1 & SIM & $\mathrm{u}$ & D & MAL & $\mathrm{u}$ \\
\hline IWGMT 90155 & & $\mathrm{H}-1$ & AVI & UNK3a-100 & $\mathrm{H}-1$ & SIM & $\mathrm{u}$ & & MAL & $\mathrm{u}$ \\
\hline IWGMT 90142 & & $\mathrm{H}-1$ & IJC & UNK1-100 & $\mathrm{H}-1$ & SIM:0.8 & $\mathrm{u}$ & $\mathrm{D}$ & MAL & $\mathrm{u}$ \\
\hline
\end{tabular}


TABLE 2-Continued

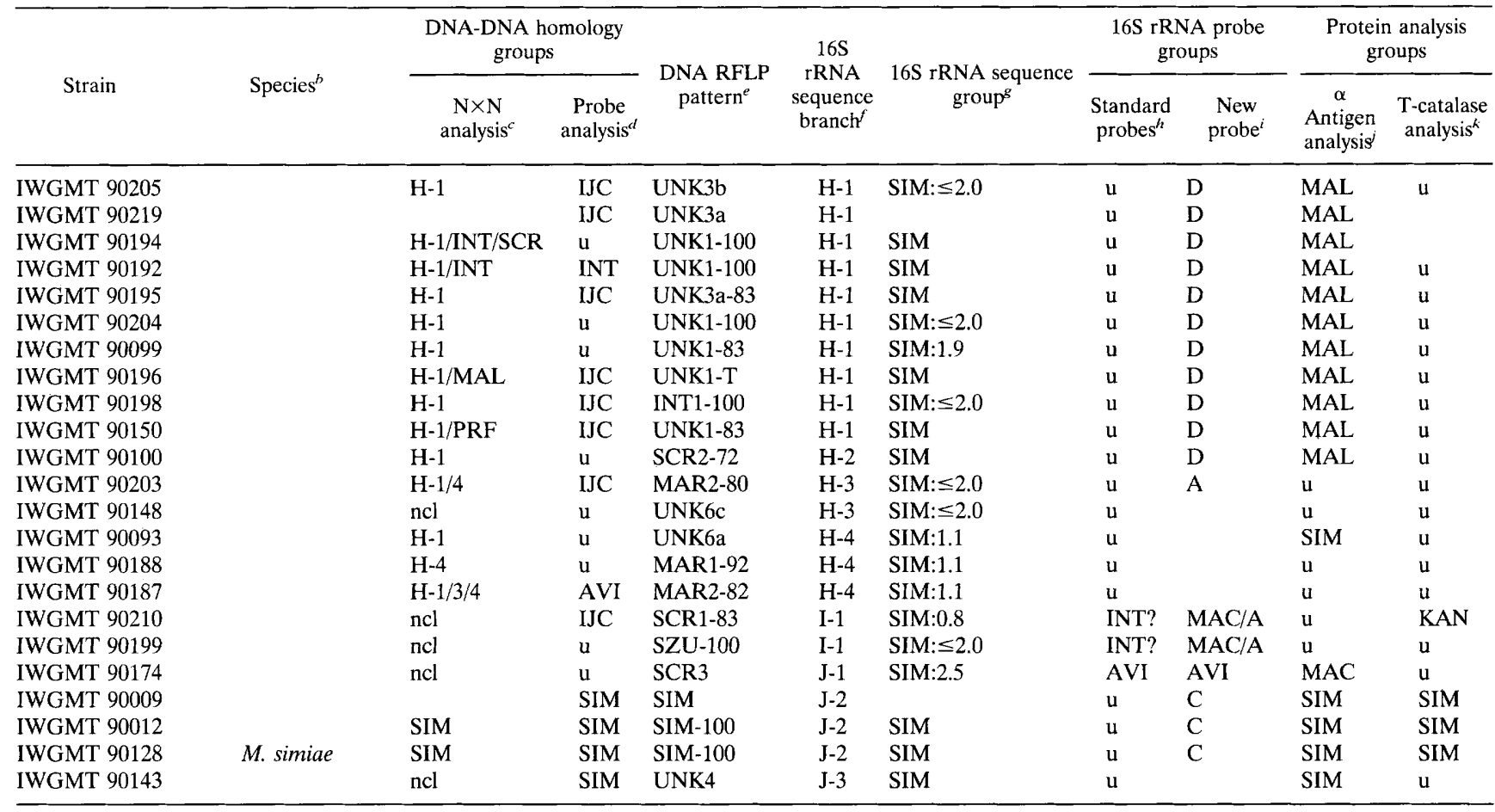

${ }^{a}$ The strains are arranged on the basis of the branches on the $16 \mathrm{~S}$ rRNA phylogenetic tree to which they belong. Designations: ASI, $M$, asiaticum; AVI, $M$. avium; FAR, $M$. farcinogenes; FLA, $M$. flavescens; GAS, $M$. gastri; GOR, $M$. gordonae; IJC, $M$. interjectum; INT, $M$. intracellulare; KAN, $M$. kansasii; MAC, $M$. avium-M. intracellulare complex; MAL, M. malmoense; MAR, M. marinum; NON, M. nonchromogenicum; PRF, "M. paraffinicum"; SCR, $M$. scrofulaceum; SIM, $M$. simiae; SZU, M. szulgai; TER, M. terrae; TRI, M. triviale; TUB, M. tuberculosis; XEN, $M$. xenopi; UNK, unknown. A space indicates that the test was not done.

${ }^{b}$ The culture used in this study was derived from the type strain of the species indicated.

${ }^{c}$ Determined in laboratory $\mathrm{J}$.

${ }^{d}$ Determined in laboratory $\mathrm{Q}$.

e Determined in laboratory $\mathrm{H}$. The numbers after the hyphens are the percentages of similarity to the reference patterns.

${ }^{f}$ Determined in laboratory $\mathrm{P}$.

${ }^{g}$ Determined in laboratory I. The serovars of strains used as references for the sequences are indicated as follows: v12, serovar $12 ; \mathrm{v} 7$, serovar $7 ; \mathrm{v} 7 / 18$, serovar 7 or 18 ; 4 , serovar 4 . The values after the colons are the percentages of difference between the sequence of the strain and the sequence of the reference strain; values of $0.5 \%$ or less are not shown.

${ }^{h}$ Determined in laboratories $\mathrm{A}$ and $\mathrm{M}$.

Determined in laboratory B.

Determined in laboratory $\mathrm{K}$.

${ }^{k}$ Determined in laboratory $\mathrm{N}$.

$\mathrm{u}$, strain could not be identified with any of the probes used.

${ }^{m}(t-)$, no T-catalase was detected by the direct enzyme assay.

${ }^{n}$ noamp, no amplification was achieved.

oncl, strain did not exhibit relatedness to any cluster in the DNA-DNA hybridization experiments.

and C-4.2, exhibited high levels of affinity with $M$. scrofulaceum patterns. High levels of internal consistency were observed with strains on branch $\mathrm{C}-1$, which includes the type strain of $M$. malmoense, and with strains on branches $\mathrm{J}-2$ and $\mathrm{J}-3$, which include the type strain of $M$. simiae. A major novel pattern was observed with branch $\mathrm{H}-1$ strains and was designated "UNK1 "; members of this branch also produced novel patterns "UNK-3a" and "UNK-3b." Other previously unrecognized patterns were scattered throughout the rest of the branches.

Protein studies. The identities of strains determined by using cross-absorbed antibodies to the $\alpha$ antigens in laboratory $K$ revealed striking levels of internal cluster consistency (Table 2 ). The identities, however, did not always agree with the identities determined by other semantide-based methods. The "MAC" antibody probe was not designed to distinguish between $M$. avium and $M$. intracellulare, and all of the strains on branches B-1 through B-5 reacted with this probe. Of special interest was the placement of cluster B-6 and B-8 strains in $M$. scrofulaceum by this method. Also of interest were the consis- tent positive reactions observed with members of both branch $\mathrm{C}-1$ ( $M$. malmoense) and new branch $\mathrm{H}-1$ when they were tested with the nominal $M$. malmoense antibody probe.

Using cross-absorbed antibodies to T-catalases in the intrinsic enzyme immunoblot test, workers in laboratory $\mathrm{N}$ identified the type strains of a number of species. Use of these antibodies also resulted in consistent identification of members of branch B-5, which includes the type strain of $M$. intracellulare, and branch B-9, which includes the type strain of $M$. avium (Table 2). On the other hand, most strains on branches B-1, B-2, B-3, B-6, and B-8 did not react with either the $M$. intracellulare probe or the $M$. avium probe. No antibody probes for the T-catalases of members of branch C-1 (M. malmoense) or new branches $\mathrm{H}-1$ through $\mathrm{H}-4$ were available.

Chemotaxonomic studies. Workers in laboratory $\mathrm{C}$ recognized 19 different mycolate HPLC patterns produced by the distributed strains (Table 3 ). All of the $M$. malmoense strains tested produced pattern 17 , which was produced by members of no other branch, and all of the $M$. simiae strains tested 


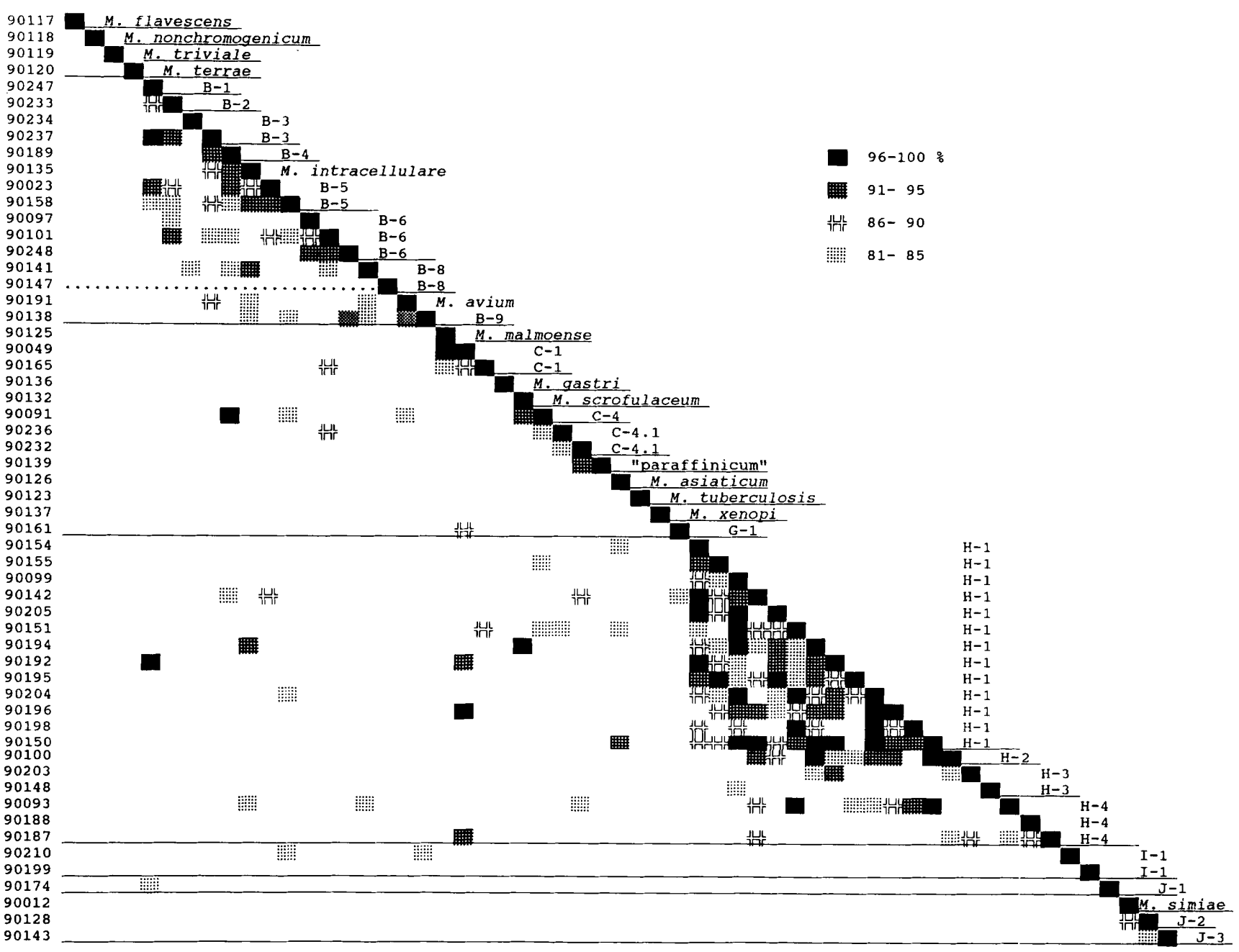

FIG. 6. Distribution of DNA-DNA hybridization values for all strain pairs examined by the fluorimetric membrane method in laboratory J. The strains were manually grouped on the basis of the branches on the 16S rRNA phylogenetic trees (Fig. 2 and 3) that were occupied by the strains. A name following a strain line indicates that the culture used was derived from the type strain of the species named.

produced pattern 11. Of the 14 strains on new branch $H-1,13$ produced pattern 9 , which was also produced by individual strains on branches $\mathrm{H}-3$ and $\mathrm{H}-4$. Branch B-5, which included the type strain of $M$. intracellulare, was made up mainly of pattern 5 strains, and branch B-9, which included the type strain of $M$. avium, consisted of pattern 13 strains. However, patterns 5,7 , and 13 also were produced frequently by members of other branches on limbs B and C of the tree, which encompassed strains related to $M$. intracellulare, $M$. avium, and $M$. scrofulaceum, and were produced irregularly by members of other branches as well. The other patterns were predominantly isolated patterns produced by the other type strains in the collection.

The composite TLC and GC lipid patterns reported by workers in laboratory $\mathrm{D}$ appeared to have different levels of specificity than the mycolate HPLC analysis patterns discussed above (Table 3). All of the strains belonging to the $M$. avium- $M$. intracellulare complex (branches B-1 through B-9), as well as the strains on the $M$. scrofulaceum-related branches (branches C-4, C-4.1, and C-4.2), produced pattern B-b. This pattern was also produced by a few isolated members of other branches as well. Pattern C-e was the predominant pattern produced by members of branches $\mathrm{H}-1, \mathrm{H}-3$, and $\mathrm{H}-4$, although other unique patterns were also produced by members of these branches. $M$. simiae strains produced pattern D-f. The other patterns were predominantly isolated patterns produced by the other type strains in the collection.

The major MLEE patterns reported by workers in laboratory $F$ were designated MLEE 1 through MLEE 9, and decimal subdivisions were used to distinguish members that differed in the mobility of only one enzyme pair. It was found that all of the strains on new branch $\mathrm{H}-1$ produced pattern MLEE 5.4, MLEE 5.5, or MLEE 5.6 (Table 3). These and other MLEE 5 patterns were also produced by members of other branches. It was not possible to determine whether two similarly coded patterns were exactly the same, however, since the actual mobilities of the enzymes from different strains may have differed, even though they were designated fast, medium, or slow.

The serovar data shown in Table 3 were obtained from the data used to prepare a previous report concerning the phenotypic open-ended study of slowly growing mycobacteria (32). Most of the strains used in this study could not be placed in known serovars. We have reported previously (33) that 20 strains representing $M$. avium and $M$. intracellulare serovars 1 through 6,8 through 11 , and 21 all reacted like $M$. avium strains, as determined by a Gen-Probe analysis and by a Tcatalase serology analysis. Similarly, almost all 25 strains rep- 


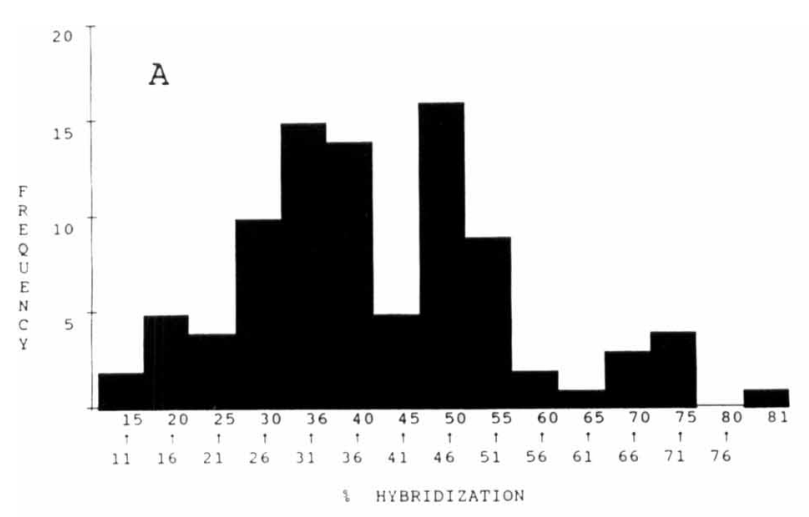

B

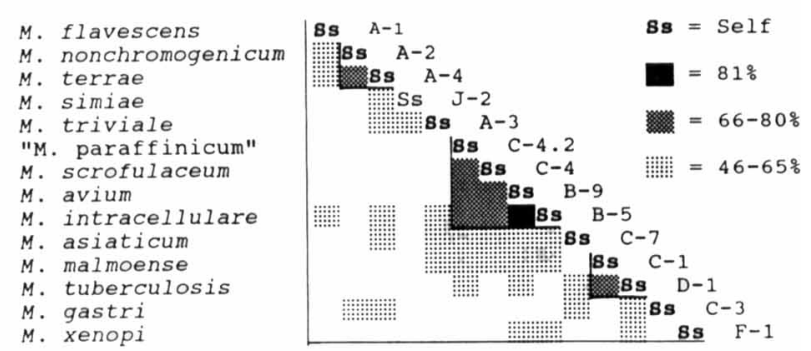

FIG. 7. Distribution of DNA-DNA hybridization values for the 91 strain pairs representing the type strains of 14 species of mycobacteria, as determined by the fluorimetric membrane method in laboratory J. (A) Composite frequency distribution based on hybridization values. (B) Clustering of type strains based on strain pair hybridization values.

resenting $M$. avium-M. intracellulare serovars 7, 12 through 20 , 23 , and 25 included in the previous study were identified by these probes as $M$. intracellulare strains. The species designations of members of other serovars in this series were considered problematic. Some of the strains of other serovars used in this study (e.g., serovar 24 and 26 strains) were members of branch B-3 which did not react with the commercial $M$. intracellulare Gen-Probe probe. Among other established species, strains of $M$. malmoense were fairly uniform in agglutinating in the presence of the "malmoense" antiserum, and, as has been noted previously, strains of $M$. simiae belong to serovars $\mathrm{S}-1$, S-2, and 18; serovar 18 also appears among strains of $M$. intracellulare (33). No serovar has yet been ascribed to new branch $\mathrm{H}-1$.

Phenotypic characterization of branches. The frequencies of occurrence of some phenotypic characteristics that have been recognized as having the greatest diagnostic power (32) are shown for the branches of greatest interest in Table 4. (For the purposes of Table 4 the strains were grouped by 16S rRNA branch rather than NT cluster.) The strains used were selected for this study because of the ambiguity of their taxonomic positions based on their phenotypic properties, so it is not surprising that the branches are not unequivocally circumscribed by these properties. Nevertheless, some distinctions between some branches and known species can be made; for comparative purposes, the frequencies of occurrence in established species described in our previous report (32) were used as reference values, but are not reported in this paper.

Overall, the properties of members of branches B-1 through B-5 are sufficiently similar to the properties of $M$. intracellulare to justify treating them as representatives of that species. Only the positive acid phosphatase reactions in branch B-5 strains differ from the results obtained for the majority of $M$. intracellulare strains. The high catalase responses of four of the branch B-6 strains, the absence of pyrazinamidase activity in three of these strains, and the scotochromogenicity of three of them reinforce the ambiguity of the taxonomic positions of members of this branch. Similarly, the heterogeneity of responses to enzymatic tests among the branch B-8 strains makes interpretation of their status difficult. The strains on branch B-9, which includes the type strain of $M$. avium, were notably consistent in their responses to the selected powerful diagnostic phenotypic tests, despite the fact that they resolved into two divergent clusters when a very broad range of properties was used for NT analysis.

16S rRNA branch $\mathrm{H}-1$, corresponding to NT cluster 7, is of special interest. As pointed out previously (32), branch $\mathrm{H}-1$ strains can easily be mistaken for $M$. gordonae when only a limited number of the most common phenotypic diagnostic tests are used. Since M. gordonae is rarely, if ever, the cause of human disease (35) and members of cluster 7 have been reported to be pathogens (32), distinction between these taxa is important. The main distinguishing phenotypic characteristics which we observed in this study (Table 4) were the positive nicotinamidase and pyrazinamidase reactions in most of the branch $\mathrm{H}-1$ strains and the low-level catalase reactions in some of the branch H-1 strains. The frequencies of occurrence for the phenotypic properties shown in Table 4 were essentially the same for branches $\mathrm{H}-1$ through $\mathrm{H}-3$, but none of the three branch $\mathrm{H}-4$ strains was scotochromogenic.

\section{DISCUSSION}

There were three main objectives of this study. One objective was to determine whether we could establish consistent criteria for using the depth of branching in 16S rRNA-based phylogenetic trees of slowly growing mycobacteria to help define new species in a polyphasic taxonomic sense (18). Another goal was to investigate the taxonomic status of a selected set of slowly growing mycobacteria that had resisted satisfactory classification in previous studies that were based on conventional phenotypic criteria (32). And the third objective was to evaluate the roles that a variety of semantide-based (37) and chemotaxonomic methods of analysis can play in identification of strains at the species, subspecific, and infrasubspecific levels.

Criteria for defining species. The generally agreed upon standard for defining the borders of bacterial species is based upon DNA-DNA hybridization data, which reflect the levels of relatedness of entire genomes (26). However, the availability of resources and technology for rapidly determining nucleotide sequences in selected regions of 16S rRNAs has led to some attempts to base phylogenetic schemes on levels of 16S rRNA homology alone (13). While these methods yield excellent data and do provide insights into evolutionary relationships at the higher taxonomic levels in bacteria, it is not yet clear how to apply these methods to resolution at the species level. This is in part related to the fact that a limited conserved region of the entire genome is reflected by the 16S rRNA genes and the fact that the depth of branching reflects in part the age of a particular branch; interspecies depth of branching may differ from genus to genus and even within a genus, as has been discussed in detail by Stackebrandt and Goebel (18). A polyphasic approach to bacterial taxonomy (3) requires consideration of relatedness of semantides at at least the primary and secondary levels (37) and correlation with chemotaxonomic and other phenotypic properties, and this was the intent of this study. As 
TABLE 3. Chemotaxonomic characterization of mycobacterial strains ${ }^{a}$

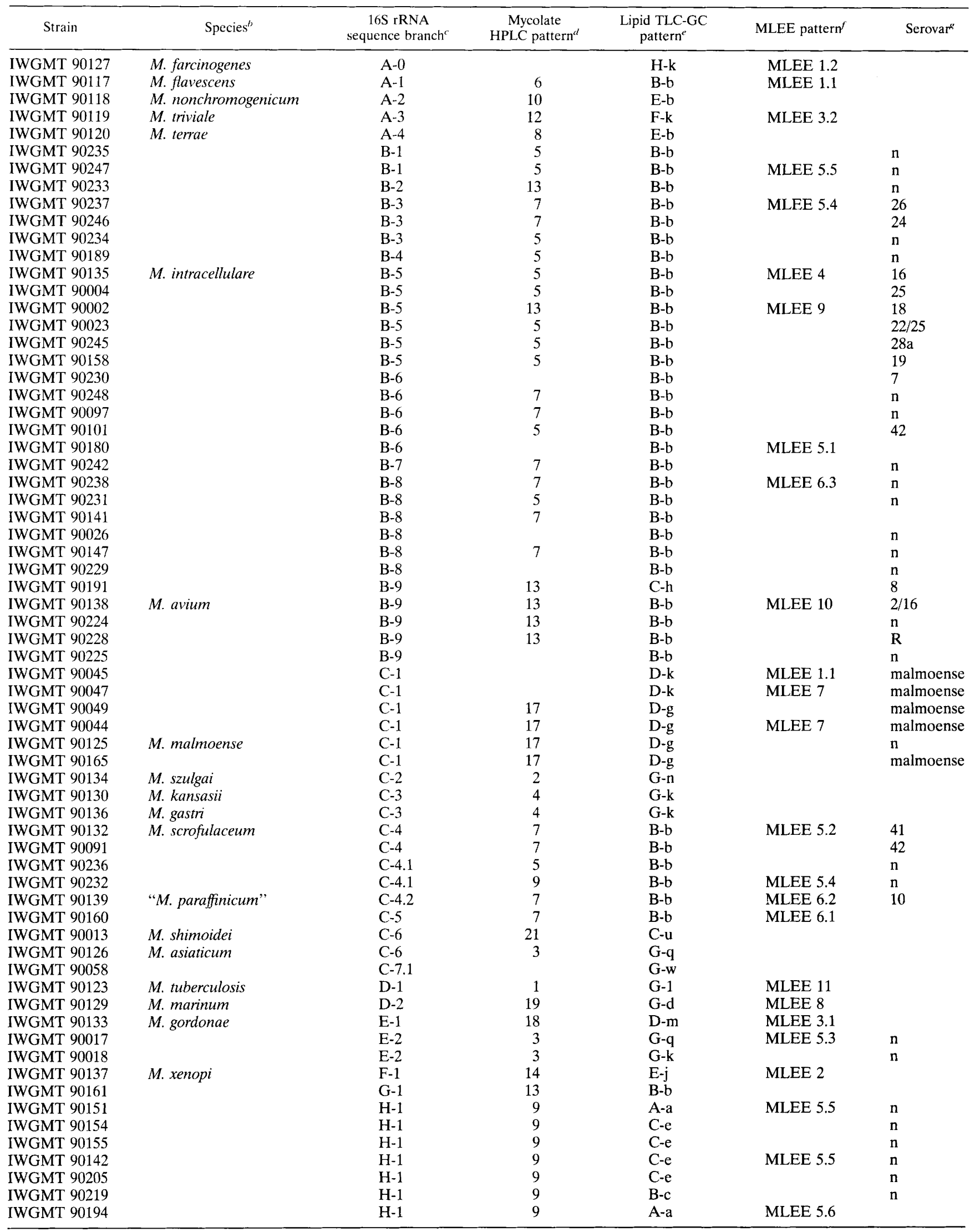


TABLE 3-Continued

\begin{tabular}{|c|c|c|c|c|c|c|}
\hline Strain & Species $^{b}$ & $\begin{array}{c}\text { 16S rRNA } \\
\text { sequence branch }\end{array}$ & $\begin{array}{c}\text { Mycolate } \\
\text { HPLC pattern }\end{array}$ & $\begin{array}{l}\text { Lipid TLC-GC } \\
\text { pattern }^{e}\end{array}$ & MLEE pattern ${ }^{\prime}$ & Serovar \\
\hline IWGMT 90192 & & $\mathrm{H}-1$ & 9 & & & $\mathrm{n}$ \\
\hline IWGMT 90195 & & $\mathrm{H}-1$ & 9 & $A-a$ & & $\mathrm{n}$ \\
\hline IWGMT 90204 & & $\mathrm{H}-1$ & 9 & B-c & & \\
\hline IWGMT 90099 & & $\mathrm{H}-1$ & 5 & C-e & MLEE 5.5 & $\mathrm{n}$ \\
\hline IWGMT 90196 & & $\mathrm{H}-1$ & 9 & A-a & & \\
\hline IWGMT 90198 & & $\mathrm{H}-1$ & 9 & B-r & MLEE 5.5 & $\mathrm{n}$ \\
\hline IWGMT 90150 & & $\mathrm{H}-1$ & 9 & B-r & MLEE 5.4 & $\mathrm{n}$ \\
\hline IWGMT 90100 & & $\mathrm{H}-2$ & 2 & G-p & & $\mathrm{n}$ \\
\hline IWGMT 90203 & & $\mathrm{H}-3$ & 9 & C-e & MLEE 5.2 & $\mathrm{n}$ \\
\hline IWGMT 90148 & & $\mathrm{H}-3$ & 15 & C-e & & $14 / 15$ \\
\hline IWGMT 90093 & & $\mathrm{H}-4$ & 2 & G-p & & $\mathrm{n}$ \\
\hline IWGMT 90188 & & $\mathrm{H}-4$ & 9 & C-e & & $\mathrm{n}$ \\
\hline IWGMT 90187 & & $\mathrm{H}-4$ & 15 & C-e & & $\mathrm{n}$ \\
\hline IWGMT 90210 & & $\mathrm{I}-1$ & 16 & D-i & & \\
\hline IWGMT 90199 & & $\mathrm{I}-1$ & 16 & G-o & & $\mathrm{n}$ \\
\hline IWGMT 90174 & & $\mathrm{~J}-1$ & 7 & B-b & & \\
\hline IWGMT 90009 & & $\mathrm{~J}-2$ & & $D-f$ & & 18 \\
\hline IWGMT 90012 & & $\mathrm{~J}-2$ & 11 & $D-f$ & & 18 \\
\hline IWGMT 90128 & M. simiae & $\mathrm{J}-2$ & 11 & D-f & & S-1 \\
\hline IWGMT 90143 & & $\mathrm{~J}-3$ & 11 & $D-f$ & & $\mathrm{~S}-2$ \\
\hline
\end{tabular}

"The strains are arranged on the basis of the branches on the 16S rRNA phylogenetic tree to which they belong.

${ }^{b}$ The culture used in this study was derived from the type strain of the species indicated.

${ }^{c}$ Determined in laboratory $\mathrm{P}$.

"Determined in laboratory $\mathrm{C}$.

${ }^{e}$ Determined in laboratory D.

${ }^{f}$ Determined in laboratory $\mathrm{F}$.

g The serovar data were derived from the data generated in a previous IWGMT open-ended phenetic study of slowly growing mycobacteria (32). n, strain did not agglutinate with any of the typing sera used. R, rough; spontaneous agglutination occurred.

noted previously (24), "A natural classification, as opposed to an arbitrary one, depends on discontinuities between sets. That is, there should be clusters of strains that are very similar to one another, but members of each cluster should be quite different from members of the nearest neighboring cluster....When we examine certain parameters at the molecular level, we see....polymodal distributions that suggest a natural division of bacteria into hierarchies...."

Attempts to establish a correlation between the Hamming distances of the 16S rRNA sequences of members of the branches and their DNA-DNA hybridization values were complicated by the fact that participants used relatively new techniques to measure DNA relatedness. In one laboratory hybridization was performed in microwell plates by using a selected set of reference DNA species standards and an enzyme-linked colorimetric assay (7). The reference standard that yielded the highest value was considered to represent the species of the unknown, as long as the second highest value did not exceed $70 \%$ of the highest value, a value that has been recommended for interpreting conventional hybridization data (26). This method was originally developed so that it could be used for identifying strains rather than for taxonomic classification. Although this technique carries the risk that a strain may belong to a species that is not represented in the reference panel but which matches one of the reference standards at a level more than $30 \%$ higher than any other reference standard (e.g., the reaction of the reference strain of " $M$. paraffinicum" with the $M$. scrofulaceum probe shown in Table 2), the overall results obtained in this study appear to be consistent, although not completely definitive. The occasional apparent inconsistencies may reflect problems associated with the kinetics of indicator enzyme systems in a solid-phase-liquid-phase interactive system, problems that are less important in methods that rely on direct measurements of bound radioactive label. Workers in another laboratory performed block strain pair titrations of dissolved DNA versus nitrocellulose-bound DNA and measured hybridization fluorimetrically $(19,20)$. This technique yields markedly higher hybridization values than more conventional methods, and it was necessary to establish cutoff points by plotting hybridization values versus feature frequencies and identifying null points on the histograms of data obtained from strains that were derived from the type strains of known species (Fig. 7). The results of this analysis established that the species cutoff level is a level of hybridization of about $85 \%$. The presence of some isolated, scattered high values that do not represent clustering behavior (Fig. 6) cannot be explained, but these values may represent some physical problems that reflect kinetic variability in the solid phase-liquid phase interactions upon which the technique is based. Although both of the DNA-DNA hybridization techniques discussed above yielded results that were consistent and useful overall and have considerable potential for screening large numbers of strains and avoiding the use of radioisotopes, there is still a need for continued use of more conventional hybridization techniques for definitive circumscription of new species. Unfortunately, the methods used to produce large amounts of mycobacterial DNA and the methods used for single-phase liquid hybridization are time consuming, and few laboratories are prepared to continue performing these analyses. We strongly recommend that resources should be made available for one or more laboratories to prepare reference batches of DNAs from all recognized mycobacterial species and to maintain the capability of performing conventional hybridization assays between DNAs from proposed new species and previously recognized species. These reference resources should be made available at an international level to provide for consistency in future taxonomic decisions.

One striking observation that emerged from this study is that 


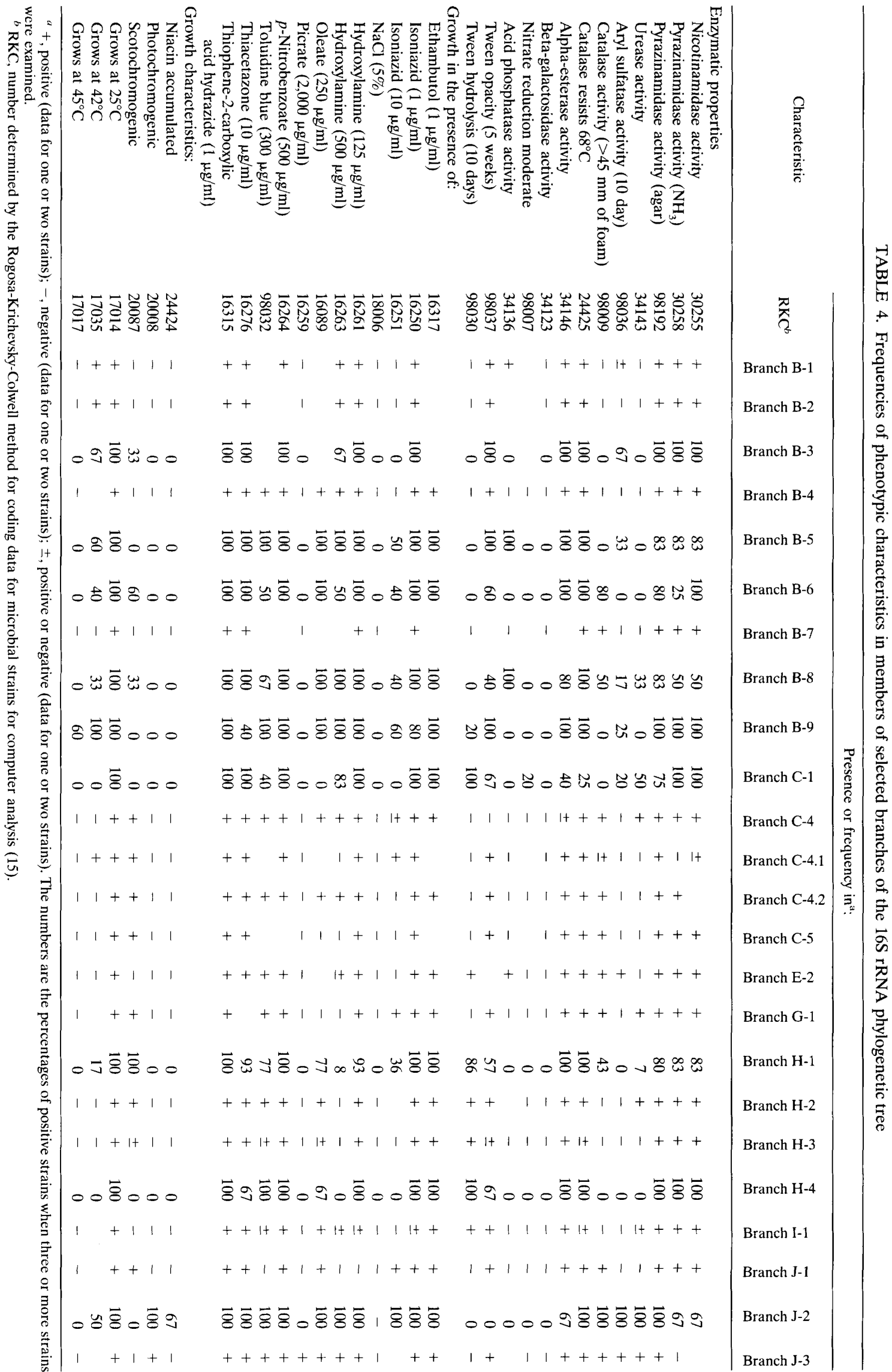


an unequivocal correlation between depth of branching on the mycobacterial 16S rRNA phylogenetic tree and the extent of DNA-DNA hybridization could not be established. We were not able to define (or even approximate) a single Hamming distance that represents the cutoff value above which two strains may be placed in different species and below which two strains must be considered members of the same species. An examination of the data suggests that sequence differences in the 16S rRNA molecules of more than 10 nucleotides probably indicate that organisms should be separated at the species level. On the other hand, the Hamming distance between the study strains derived from the type strains of $M$. szulgai and $M$. malmoense was only 2 nucleotides in the 1,384-nucleotide segment examined (Fig. 4), yet the DNA probe analysis, the DNA RFLP analysis, and the $\alpha$ antigen protein probe analysis (Table 2 ), as well as the phenetic NT analysis (Fig. 1) and lipid pattern analysis (Table 3 ), provided convincing evidence that these organisms should be placed in different species. In contrast, a comparison of branch B-1 through B-5 strains yielded interbranch Hamming distances ranging from 1 to 7 nucleotides in the 782-nucleotide segment examined, yet the results of the two DNA hybridization assays and the DNA RFLP analyses strongly indicated that these strains belong to a single species, $M$. intracellulare. $16 \mathrm{~S}$ rRNA sequence analyses are clearly very valuable for establishing evolutionary pathways, but we cannot specify a fixed Hamming distance that always defines a new species, even in a single genus, such as the genus Mycobacterium. Such decisions require individual attention in each specific case, and scientific judgment must take into account information at several semantide and phenotypic levels.

Taxonomic status of novel clusters and branches. With the caveats described above in mind, we attempted to interpret the status of some of the strains distributed for analysis in this study. The strains representing branches A0 through $\mathrm{A} 4, \mathrm{C} 2$, C3, D1, D2, E1, and F1 were all derived from type strains of recognized species, and no strains that are closely related to these strains at the semantide or phenotypic levels were included in this study. Strains derived from the type strains of some other species did exhibit affinity with other strains in the study, as discussed below.

The strains on branches B-1 through B-9 are members of the informal $M$. avium- $M$. intracellulare complex. Members of branches B-1 through B-5 appeared to represent minor variants of $M$. intracellulare (Fig. 3). The type strain of this species is on branch B-5, and the strains on this branch are the only strains that reacted with the commercially available $16 \mathrm{~S}$ rRNA probe, as well as the $T$-catalase antibody probe for $M$. intracellulare. Members of this branch differ significantly in consensus frequencies from $M$. intracellulare in the results of tests for aryl sulfatase and acid phosphatase (32); however, it must be remembered that most of the strains in this study were selected for evaluation because they were phenotypic outliers, and such deviations were expected. The results of the DNA hybridization analyses, as well as the results of other semantide-based analyses (Table 2) and chemotaxonomic characteristics (Table 3 ), support inclusion of the members of branches B-1 through B-4 in the species $M$. intracellulare; it might be appropriate to treat these taxa as ribovars, since the main differences among them are small variations in their 16S rRNA nucleotide sequences. The single member of branch B-7 probably also belongs to this group, despite an inconclusive DNA RFLP pattern; the matching scores of this strain on the phenetic NT diagram (Fig. 1) indicate that it exhibits very high affinities for most strains on branches B-1 through B-6. Some of the strains in this group probably correspond to the kinds of strains that reacted with the erstwhile " $\mathrm{X}$ " probe (Syngene, Inc., San Di- ego, Calif.), but not with the $M$. intracellulare Gen-Probe probe or the $M$. intracellulare T-catalase intrinsic enzyme probe cited in the study of Woodley et al. (36). Branch B-9 includes the type strain of $M$. avium. Even though members of branch B-9 are poorly allied on the phenetic NT diagram (Fig. 1), the results of the semantide-based analyses (Table 2) clearly confirm that they belong to $M$. avium and are distinct from $M$. intracellulare.

Interpretation of the status of members of branches B-6 and B-8 is more difficult. Both of these branches are large enough (five and six members, respectively) that it should be possible to characterize them. However, their phenotypic characteristics are confusing (Fig. 1). Two of the branch B-6 strains (IWGMT 90230 and IWGMT 90248) are closely allied with the $M$. intracellulare strains on branches B-1 through B-5 and B-7, but the other three strains (IWGMT 90097, IWGMT 90101, and IWGMT 90180) form a tight phenetic cluster with the erstwhile type strain of the invalid species " $M$. paraffinicum," which is the sole member of $16 \mathrm{~S}$ rRNA branch C-4.2. All five branch B-6 strains reacted with the $M$. intracellulare reference probe in the DNA-DNA microplate assay (Table 2), but the three branch B-6 strains that were used in the fluorescentmembrane assay clustered with each other but only questionably clustered with other strains (Fig. 1). In the DNA RFLP and $\alpha$ protein antigen assays, these strains reacted like $M$. scrofulaceum, and their lipid chromatographic patterns were the same as the patterns produced by $M$. intracellulare, $M$. avium, and $M$. scrofulaceum (Table 3 ). When the most powerful diagnostic phenotypic characteristics were used (Table 4), the majority of the branch B-6 strains exhibited scotochromogenicity and high levels of catalase reactivity, characteristics of $M$. scrofulaceum. On the basis of their location on the $16 \mathrm{~S}$ rRNA phylogenetic tree and their reactivities with the DNA reference probes, members of branch B- 6 may best be considered members of a subspecies of $M$. intracellulare for the time being, but further study of the DNA-DNA reactions of these organisms will be necessary to clarify their status.

Similarly, members of branch B-8 occur in several places on the phenetic NT diagram, but most of these strains group together in cluster 8 (Fig. 1). Members of branch B-8 have the same peculiar distributions of semantide affinities described above for branch B-6 strains (Table 2). They are especially erratic in their responses to the enzymatic tests among the diagnostic characteristics listed in Table 4. It is not possible to make a firm recommendation concerning the taxonomic status of members of $16 \mathrm{~S}$ rRNA branch B-8 at this time.

Branch $\mathrm{C}-1$ is composed of six strains, including the type strain of $M$. malmoense. Four of these six strains occurred in phenetic NT cluster 10 (Fig. 1), and the DNA hybridization data clearly placed three of them in a single species. The lipid analyses revealed minor differences in the patterns of the two other strains (IWGMT 90045 and IWGMT 90047), which occurred in an unnumbered NT cluster just above cluster 6 on the phenetic diagram (Fig. 1) and exhibited low matching values with the other members of this branch. The DNA RFLP results support placement of all six strains in the species $M$. malmoense, and the phenotypic feature frequencies based on the results of major diagnostic tests are comparable to the values published previously for this species (32).

Branch C-2 includes a single strain, the type strain of $M$. szulgai, and, as noted above, the $16 \mathrm{~S}$ rRNA sequence of this organism differs by only two nucleotides from the $M$. malmoense sequence. Nevertheless, the DNA hybridization and RFLP data, as well as the lipid patterns, support separation of $M$. szulgai and $M$. malmoense strains into two distinct species. Branch C-3 includes only two strains, which were derived from the type strains of $M$. kansasii and $M$. gastri. Branch C-4 in- 
cludes two strains, one of which was derived from the type strain of $M$. scrofulaceum and the other of which had the semantide and chemotaxonomic characteristics of that species.

Branch C-4.1 consists of two strains that are widely separated on the phenetic NT diagram (Fig. 1), but nevertheless exhibited matching scores of more than $85 \%$ with each other. The DNA hybridization and RFLP results obtained for these strains are equivocal, as are other properties. Further interpretation of the taxonomic status of the branch C-4.1 strains will depend on acquisition and study of additional strains that have the same $16 \mathrm{~S}$ rRNA nucleotide sequences.

Branch C-4.2 consists of a single strain, IWGMT 90139 , which was derived from the type strain of the invalid species "M. paraffinicum." The tight phenetic clustering observed between this organism and other strains recognized in our previous study (32) led us to believe that revival of the species " $M$. paraffinicum" might be warranted. However, as noted above, most of the strains in phenetic cluster 6 belonged to $16 \mathrm{~S}$ rRNA branch B-6, whereas strain IWGMT 90139 reacted in most cases only with semantide-based probes derived from itself; an exception was the microplate DNA-DNA assay, which included no " $M$. paraffinicum" probe, in which this strain reacted with the $M$. scrofulaceum probe (Table 2). Thus, strain IWGMT 90139 is an isolated strain that exhibits no unequivocal taxonomic relatedness to any other known culture, so the species " $M$. paraffinicum" should not be revived at this time.

The lone member of branch C-5 exhibits some semantidebased relatedness to $M$. scrofulaceum (Table 2), but its taxonomic position cannot be established until more strains are found. The branch C-6 strain was derived from the type strain of $M$. shimoidei. Branch C-7 consists of one strain that was derived from the type strain of $M$. asiaticum, and the semantide-based data clearly confirmed that the strain is a member of this species. The branch C-7.1 strain is closely related to $M$. asiaticum.

The two strains on branch E-2 clustered tightly with each other on the phenetic NT diagram (Fig. 1); the semantidebased data (Table 2) and the lipid patterns (Table 3 ) suggested that these two strains are indeed closely related to one another. Their relationship between these organisms and other species was ambiguous, although their $16 \mathrm{~S}$ rRNA signature sequences were similar to those of $M$. asiaticum. Their consistency in almost all of the characteristics examined suggested the possibility that they represent a distinct taxon, and a search for more representatives of this branch should be continued.

Branch G-1 consists of a single strain with that exhibited no marked affinity with any other strain at the phenotypic or semantide levels, although its lipid patterns resembled those of M. avium.

Phenotypic cluster 7 was singled out for special attention in our previous study because it was a large cluster whose members reacted like $M$. gordonae in most commonly used phenotypic diagnostic tests, but it differed from that species in that many of its members were considered agents that cause human disease (32). In fact, it has been speculated that the very rare cases of human disease that have been attributed to $M$. gordonae may have actually been caused by members of this novel cluster that were misidentified as $M$. gordonae (35). Of the 14 strains that belong to phenetic cluster 7 (Fig. 1), 10 belong to $16 \mathrm{~S}$ rRNA branch $\mathrm{H}-1$. Two more branch $\mathrm{H}-1$ strains occur in an unnumbered cluster just below cluster $4 \mathrm{c}$, another belongs to cluster 6 , and still another belongs to cluster 9; all four of these strains exhibit high phenetic matching scores when they are compared with members of phenetic cluster 7 and could easily have been placed in that cluster. Neither $M$. interjectum nor $M$. genavense had been described or named when the set of strains was distributed for this study, so workers did not have sequence information or probes for these new species. However, when the results of a preliminary analysis of data suggested that the branch $\mathrm{H}-1$ strains might be $M$. interjectum strains, it was suggested to the investigator in laboratory $\mathrm{Q}$ that the type strain of this new species should be obtained and its DNA should be added to the battery of reference materials used to test all strains by the microplate hybridization method. This was done without revealing the identity of any of the coded strains in the study, so the integrity of the blind assay was not compromised. The branch $\mathrm{H}-1$ strains (Fig. 2) form a tight cluster as determined by the fluorescent-membranebased DNA-DNA hybridization assay (Fig. 6), and most of them react in the microplate hybridization assay with the reference DNA probe from $M$. interjectum, a new species that was isolated from two specimens obtained from one child with chronic lymphadenitis (16). The branch H-1 16S rRNA nucleotide pattern of exhibits a Hamming distance of only 2 nucleotides from the $M$. interjectum pattern (Fig. 4C). All branch $\mathrm{H}-1$ strains reacted specifically with new $16 \mathrm{~S}$ rRNA probe $\mathrm{D}$ in laboratory $\mathrm{B}$; as noted above, this probe was originally considered by its developer to be potentially useful for identifying $M$. haemophilum. It is interesting that most members of branch $\mathrm{H}-1$ had nucleotide sequences that corresponded to the sequences of $M$. simiae when the region used by workers in laboratory I was examined. Members of this branch produce some novel DNA RFLP patterns and react with the $M$. malmoense $\alpha$ antigen protein probe (Table 2). They also produce a unique and consistent HPLC mycolate pattern and several different novel lipid TLC and GC patterns (Table 3). The data obtain provide convincing evidence that the strains on branch $\mathrm{H}-1$ belong to the new species $M$. interjectum.

Three other minor branches appear on the limb that bears $M$. interjectum and branch $\mathrm{H}-1$. The lone strain on branch $\mathrm{H}-2$, which exhibited Hamming distances of 3 nucleotides from branch $\mathrm{H}-1$ and 5 nucleotides from $M$. interjectum, exhibited high levels of DNA-DNA hybridization with most members of branch $\mathrm{H}-1$ in the fluorescent-membrane test, but was not identified in the microplate hybridization test or the RFLP analysis. This strain was the only strain other than the strains on branch $\mathrm{H}-1$ that reacted with probe $\mathrm{D}$ in laboratory $\mathrm{B}$, and it fell well within phenetic NT cluster 7 (Fig. 1); however, it was urease positive (Table 4), and its lipid patterns were not consistent with those of members of branch H-1 (Table 3). Similar problems occurred with the two strains on branch $\mathrm{H}-3$. The status of the three strains on branch $\mathrm{H}-4$ is even more unclear. The 16S rRNA pattern that represents this branch differs from the patterns of $M$. interjectum and branches $\mathrm{H}-1, \mathrm{H}-2$, and $\mathrm{H}-3$ by Hamming distances of $12,10,7$, and 8 nucleotides, respectively (Fig. 4C), and the DNA hybridization results do not resolve the relatedness (Table 2). The lipid patterns are consistent with some patterns observed in branch $\mathrm{H}-1, \mathrm{H}-2$, and $\mathrm{H}-3$ strains. The frequency distribution of the responses of the branch $\mathrm{H}-4$ strains in the major diagnostic tests is similar to the frequency distribution of the branch $\mathrm{H}-1$ strains, except that the branch $\mathrm{H}-4$ strains are not chromogenic. Thus, the taxonomic status of the six strains that make up branches $\mathrm{H}-2, \mathrm{H}-3$, and $\mathrm{H}-4$ remains unclear, but these organisms may represent ribovars and/or subspecies of $M$. interjectum.

Branch I-1 comprises two strains, IWGMT 90210 and IWGMT 90199, which are widely separated from each other on the phenetic NT diagram and which exhibited no notable level of relatedness with each other in any semantide analysis other than the $16 \mathrm{~S}$ rRNA sequence analysis performed in laboratory $\mathrm{P}$ or in the chromatographic behavior of their lipids, as determined in laboratory D. They do share a unique HPLC myco- 
late pattern (Table 3). No conclusions concerning the taxonomic status of these organisms can be reached on the basis of the data available at this time, although they do share a major limb on the $16 \mathrm{~S}$ rRNA phylogenetic tree with $M$. simiae and $M$. genavense (Fig. 2).

Branch J-2 includes the strain derived from the type strain of $M$. simiae and two other strains that have the same semantide and chemotaxonomic characteristics (Tables 2 and 3). The single strain on branch J-3 exhibits a 16S rRNA Hamming distance of only three nucleotides from branch J-2 (Fig. 4C) and shares other semantide and chemotaxonomic characteristics with branch $\mathrm{J}-2$, but it produces a unique DNA RFLP pattern; this organism may reasonably be considered a ribovar of $M$. simiae. The single member of branch J-1 yielded ambiguous results in the semantide analyses; it reacted with the $M$. avium commercial RNA probe but not with the $M$. avium reference DNA, and its taxonomic status could not be established from the data available.

Roles of different methods and parameters in polyphasic classification and identification of mycobacteria. The data obtained in this study permitted us to evaluate the roles that each of the techniques used can play in the systematic study of mycobacteria. At the primary semantide level, DNA-DNA hybridization, which reflects the affinity of the whole genome, continues to offer the most consistent criterion (i.e., $70 \%$ hybridization under stringent conditions $[18,26]$ ) for establishing whether two strains belong to the same species and thus for establishing the existence of new species. Because of the limited range over which DNA-DNA hybridization can be determined with reasonable accuracy, this method is not useful for assessing evolutionary pathways or distances at taxonomic levels beyond the species level. The two DNA hybridization methods used in this study were based on interactions between dissolved DNA samples and immobilized samples. Presumably because it is more difficult to control the kinetics of reactions that occur in two-phase (liquid-solid) systems than the kinetics of reactions that occur in single-phase liquid systems, the twophase systems are considered less quantitative than the liquid hybridization systems (5). This may explain some of the apparent inconsistencies observed in the DNA-DNA hybridization results obtained in this study. The membrane fluorimetric method used by workers in laboratory $\mathbf{J}(19,20)$ was useful for cross-titrating multiple strains, and the data provided by these workers were used to generate a block triangular homology diagram and defined the appropriate species cutoff level $(85 \%)$ for this technique. The utility of this method for taxonomy would be enhanced if factors that were responsible for the inconsistencies could be identified and corrected. The colorimetric microplate method used by workers in laboratory $\mathrm{Q}$ was originally intended to be used for identification rather than classification purposes (7), and it requires the use of a reference sample derived from every possible species. Although the requirement that the highest binding value must exceed the second highest value by at least $30 \%$ reduces the chance of a false identification, it does not eliminate that possibility (see "M. paraffinicum" in Table 2). One way to resolve this problem would be to include an immobilized sample of the homologous organism in one well of the test plate when an unknown organism is tested, thus establishing a value for the "true $100 \%$ " reaction, and to accept as definitive only an value that was at least $70 \%$ as high. With this modification, the potential for using this method for classification as well as identification would be enhanced.

Although DNA RFLP patterns that appear to be characteristic of certain species can be recognized, it is clear from the data presented above that a number of different patterns are produced by members of individual mycobacterial species. Thus, this technique is most useful in epidemiologic or ecologic studies in which tracing individual strains is the major objective.

The most precise method for assessing levels of relatedness between primary or secondary semantides of different taxa is actually determining nucleotide sequences. DNA sequencing of the entire genome is clearly impractical. On the other hand, it is practical to determine the sequence of the DNA that codes for a region of a secondary semantide (RNA) that appears to encompass the desired degree of conservation for the purpose at hand. This was done in this study with $16 \mathrm{~S}$ rRNA, and the phylogenetic trees that were obtained appeared to reflect evolutionary pathways. However, the apparent depth of branching, influenced as it was by the time in the past when bifurcations of the tree occurred (18), the region selected for sequencing, and the algorithm chosen to analyze it, was not a reliable index of the cutoff level for establishing species borders, varying from 2 to 7 substitutions and/or deletions. Once a species has been identified by a polyphasic strategy in which 16S rRNA sequencing, DNA-DNA hybridization, and phenotypic characterization are used, the sequences in selected regions can be used to identify individual strains. Alternatively, the DNA coding for selected subregions of the RNA can be reproduced in the form of probes that can be used to identify strains at different desired levels of specificity, as shown by the results obtained with a variety of probes (Table 2).

Antibody probes for individual proteins can serve a function similar to the function served by RNA probes. The data derived from application of cross-absorbed antibody probes to immunodiffusion recognition of $\alpha$ antigen protein $(21,22)$ or to a multidot panel for identification of intrinsic T-catalase (27) indicated that such antibody probes can identify mycobacteria at specific and subspecific levels and probably can be tailored, through appropriate levels of cross-absorption and the use of mixtures of probes, to provide identification at any level desired. An advantage of these methods is that demands on sophisticated technical skills and equipment needs are minimal. The mycobacterial MLEE technique appears to be a technique that is best suited to epidemiologic or ecologic applications, since different patterns are evident within species. The systematic utility of this method would be enhanced if workers recorded actual distances of migration, rather than simply divided the migration rates into the three categories used in this study. This would probably have eliminated some of the apparently identical patterns observed with different species (Table 3 ).

The three chemotaxonomic techniques used to characterize mycobacterial lipids (HPLC, TLC, and GC) yielded various degrees of resolution within the genus (Table 3). In some cases, most notably $M$. malmoense, $M$. interjectum, and $M$. simiae, the HPLC patterns appeared to be species specific; in other cases (e.g., M. intracellulare) they subdivided species; and in still other cases they crossed species lines. The combined TLC and GC patterns exhibited a similar range of distribution specificities, except that their distributions differed from those of the HPLC data, in some cases extending above the species level. For example, pattern B-b was found very consistently in $M$. intracellulare, $M$. avium, $M$. scrofulaceum, and members of closely allied 16S rRNA branches, such as branches C-4.1 and C-4.2. Two patterns were observed with $M$. malmoense strains, and four patterns were observed with $M$. interjectum strains. Particularly interesting is the fact that the results of all of the lipid analysis methods distinguished $M$. interjectum from the type strain of $M$. gordonae, a fact of considerable practical significance. Lipid analyses appear to be most useful for identifying mycobacteria when they are used in combination with some 
supplementary tests that resolve cases in which a pattern occurs in more than one species.

\section{ACKNOWLEDGMENTS}

This study was supported in part by the Medical Research Service of the Department of Veterans Affairs.

The technical assistance of Suzanne Glickmann (Centers for Disease Control and Prevention, Atlanta, Ga.) is acknowledged.

\section{REFERENCES}

1. Arnold, L. J., Jr., P. W. Hammond, W. A. Wiese, and N. C. Nelson. 1989. Assay formats involving acridinium-ester-labelled DNA probes. Clin. Chem. 35: $1588-1594$

1a.Böddinghaus, B., J. Wolters, W. Heikens, and E. C. Böttger. 1990. Phylogenetic analysis and identification of different serovars of Mycobacterium intracellulare at the molecular level. FEMS Microbiol. Lett. 70:197-204.

2. Butler, W. R., K. C. Jost, Jr., and J. O. Kilburn. 1991. Identification of mycobacteria by high-performance liquid chromatography. J. Clin. Microbiol. 29:2468-2472.

3. Colwell, R. R. 1970. Polyphasic taxonomy of bacteria, p. 421-436. In $\mathrm{H}$ Iizuka and T. Hasegawa (ed.), Culture Collections of Microorganisms. Proceedings of the International Conference on Culture Collections. University of Tokyo Press, Tokyo.

4. Daffé, M., A. Varnerot, and V. V. Lévy-Frébault. 1992. The phenolic mycoside of Mycobacterium ulcerans: structure and taxonomic implications. J. Gen. Microbiol. 138:131-137.

4a.Fitch, W. M. 1981. A non-sequential method for constructing trees and hierarchical classifications. J. Mol. Evol. 18:30-37.

5. Johnson, J. L. 1993. Similarity analysis of DNAs, p. 655-682. In P. Gerhardt, R. G. E. Murray, W. A. Wood, and N. R. Krieg (ed.), Methods for General and Molecular Bacteriology. American Society for Microbiology, Washington, D.C.

6. Kirschner, P., B. Springer, U. Vogel, A. Meier, A. Wrede, M. Kiekenbeck, F.-C. Bange, and E. C. Böttger. 1993. Genotypic identification of mycobacteria by nucleic acid sequence determination: report of a 2 -year experience in a clinical laboratory. J. Clin. Microbiol. 31:2882-2889.

7. Kusunoki, S., T. Ezaki, M. Tamesada, Y. Hatanaka, K. Asano, Y. Hashimoto, and E. Yabuuchi. 1991. Application of colorimetric microdilution plate hybridization for rapid genetic identification of 22 Mycobacterium species. J. Clin. Microbiol. 29:1596-1603.

8. Lebrun, L., F. Espinasse, J. D. Poveda, and V. V. Levy-Frebault. 1992. Evaluation of nonradioactive DNA probes for identification of mycobacteria. J. Clin. Microbiol. 30:2476-2478.

9. Levy-Frebault, V. V., and F. Portaels. 1992. Proposed minimal standards for the genus Mycobacterium and for description of new slowly growing $\mathrm{Myco}$ bacterium species. Int. J. Syst. Bacteriol. 42:315-323.

9a.Meier, A., P. Kirschner, K.-H. Schroeder, J. Wolters, R. M. Kroppenstedt, and E. C. Böttger. 1993. Mycobacterium intermedium sp. nov. Int. J. Syst. Bacteriol. 43:204-209.

10. Meissner, G., K. H. Schroder, G. E. Amadio, W. Anz, S. Chaparas, H. W. B. Engel, P. A. Jenkins, W. Kappler, H. H. Kleeberg, E. Kubala, M. Kubín, D. Lauterbach, A. Lind, M. Magnusson, Z. Mikova, S. R. Pattyn, W. B. Schaefer, J. L. Stanford, M. Tsukamura, L. G. Wayne, I. Willers, and E. Wolinsky. 1974. A cooperative numerical analysis of nonscoto- and nonphotochromogenic slowly growing mycobacteria. J. Gen. Microbiol. 83:207-235.

11. Plikaytis, B. B., B. D. Plikaytis, M. A. Yakrus, W. R. Butler, C. L. Woodley, V. A. Silcox, and T. M. Shinnick. 1992. Differentiation of slowly growing Mycobacterium species, including Mycobacterium tuberculosis, by gene amplification and restriction fragment length polymorphism analysis. J. Clin. Microbiol. 30:1815-1822.

12. Ridell, M. 1993. Enzyme electrophoresis in taxonomy of mycobacteria. Ann. Soc. Belg. Med. Trop. 73(Supp. 1):35-39.

13. Rogall, T., J. Wolters, T. Flohr, and E. C. Böttger. 1990. Towards a phylogeny and definition of species at the molecular level within the genus $M y \mathrm{CO}^{-}$ bacterium. Int. J. Syst. Bacteriol. 40:323-330.

14. Rogosa, M., M. I. Krichevsky, and R. R. Colwell. 1971. Method for coding data on microbial strains. Int. J. Syst. Bacteriol. 21:1A-175A.

15. Sneath, P. H. A., and R. R. Sokal. 1973. Numerical taxonomy. W. H. Freeman and Co., San Francisco.

16. Springer, B., P. Kirschner, G. Rost-Meyer, K.-H. Schröder, R. M. Kroppenstedt, and E. C. Böttger. 1993. Mycobacterium interjectum, a new species isolated from a patient with chronic lymphadenitis. J. Clin. Microbiol. 31: 3083-3089.

17. Stackebrandt, E., and M. Dorsch. 1992. Some modifications in the procedure of direct sequencing of PCR amplified 16S rDNA. J. Microbiol. Methods 16:271-279.

18. Stackebrandt, E., and B. M. Goebel. 1994. Taxonomic note: a place for DNA-DNA reassociation and 16S rRNA sequence analysis in the present species definition in bacteriology. Int. J. Syst. Bacteriol. 44:846-849.

19. Sverdlov, F. D., G. S. Monastyrskaya, L. I. Guskova, T. L. Levitan, V. I.
Sheichenko, and E. I. Budowsky. 1974. Modification of cytidine residues with a bisulfite-O-methylhydroxylamine mixture. Biochim. Biophys. Acta 340: 153-165.

20. Tarnok, S., I. Tarnok, and A. Tarnok. 1992. DNA-DNA homologies in the taxonomy of mycobacteria: estimation of genetic relationships using sulfonated total-DNA and 4-methylumbelliferyl phosphate (UBFP). Klin. Lab. 38:340-342.

21. Tasaka, H., K. Kiyotani, and Y. Matsuo. 1983. Purification and antigenic specificity of alpha protein (Yoneda and Fukui) from Mycobacterium tuberculosis and Mycobacterium intracellulare. Hiroshima J. Med. Sci. 32:1-8.

22. Tasaka, H., T. Nomura, and Y. Matsuo. 1985. Specificity and distribution of alpha antigens of Mycobacterium avium-intracellulare, Mycobacterium scrofulaceum, and related species of mycobacteria. Am. Rev. Respir. Dis. 132:173-174.

23. Walczak, C. A., and M. I. Krichevsky. 1980. Computer methods for describing groups from binary phenetic data: preliminary summary and editing of data. Int. J. Syst. Bacteriol. 30:615-621.

24. Wayne, L. G. 1978. Mycobacterial taxonomy: a search for discontinuities. Ann. Microbiol. Inst. Pasteur 129:13-27.

25. Wayne, L. G., L. Andrade, S. Froman, W. Kappler, E. Kubala, G. Meissner, and M. Tsukamura. 1979. A co-operative numerical analysis of Mycobacterium gastri, Mycobacterium kansasii, and Mycobacterium marinum. J. Gen. Microbiol. 109:319-327.

26. Wayne, L. G., D. J. Brenner, R. R. Colwell, P. A. D. Grimont, O. Kandler, M. I. Krichevsky, L. H. Moore, W. E. C. Moore, R. G. E. Murray, E. Stackebrandt, M. P. Starr, and H. G. Trüper. 1987. Report of the Ad Hoc Committee on Reconciliation of Approaches to Bacterial Systematics. Int. J. Syst. Bacteriol. 37:463-464.

27. Wayne, L. G., and G. A. Diaz. 1987. Intrinsic catalase dot blot immunoassay for identification of Mycobacterium tuberculosis, Mycobacterium avium, and Mycobacterium intracellulare. J. Clin. Microbiol. 25:1687-1690.

28. Wayne, L. G., T. M. Dietz, C. Gernez-Rieux, P. A. Jenkins, W. Käppler, G. P. Kubica, J. B. G. Kwapinski, G. Meissner, S. R. Pattyn, E. H. Runyon, K. H. Schröder, V. A. Silcox, M. Tsukamura, and E. Wolinsky. 1971. A cooperative numerical taxonomic analysis of scotochromogenic slowly growing mycobacteria. J. Gen. Microbiol. 66:255-271.

29. Wayne, L. G., R. C. Good, M. I. Krichevsky, R. E. Beam, Z. Blacklock, S. D. Chaparas, D. Dawson, S. Froman, W. Gross, J. Hawkins, P. A. Jenkins, I. Juhlin, W. Kappler, H. H. Kleeberg, I. Krasnow, M. J. Lefford, E. Mankiewicz, C. McDurmont, G. Meissner, E. E. Nel, S. R. Pattyn, F. Portaels, P. A. Richards, S. Rusch, K. H. Schroder, I. Szabo, M. Tsukamura, and B. Vergmann. 1981. First report of the cooperative, open-ended study of slowly growing mycobacteria by the International Working Group on Mycobacterial Taxonomy. Int. J. Syst. Bacteriol. 31:1-20.

30. Wayne, L. G., R. C. Good, M. I. Krichevsky, R. E. Beam, Z. Blacklock, H. L. David, D. Dawson, W. Gross, J. Hawkins, P. A. Jenkins, I. Juhlin, W. Kappler, H. H. Kleeberg, I. Krasnow, M. J. Lefford, E. Mankiewicz, C. McDurmont, E. E. Nel, F. Portaels, P. A. Richards, S. Rusch, K. H. Schroder, V. A. Silcox, I. Szabo, M. Tsukamura, L. Van Den Breen, and B. Vergmann. 1983. Second report of the cooperative, open ended study of slowly growing mycobacteria by the International Working Group on Mycobacterial Taxonomy. Int. J. Syst. Bacteriol. 33:265-274.

31. Wayne, L. G., R. C. Good, M. I. Krichevsky, Z. Blacklock, H. L. David, D. Dawson, W. Gross, J. Hawkins, P. A. Jenkins, I. Juhlin, W. Kappler, H. H. Kleeberg, V. Levy-Frebault, C. McDurmont, E. E. Nel, F. Portaels, S. RuschGerdes, K. H. Schroder, V. A. Silcox, I. Szabo, M. Tsukamura, L. Vaan Den Breen, B. Vergmann, and M. A. Yakrus. 1989. Third report of the cooperative, open-ended study of slowly growing mycobacteria by the International Working Group on Mycobacterial Taxonomy. Int. J. Syst. Bacteriol. 39:267-278.

32. Wayne, L. G., R. C. Good, M. I. Krichevsky, Z. Blacklock, H. L. David, D. Dawson, W. Gross, J. Hawkins, V. V. Levy-Frebault, C. McManus, F. Portaels, S. Rüsch-Gerdes, K. H. Schröder, V. A. Silcox, M. Tsukamura, L. Van Den Breen, and M. A. Yakrus. 1991. Fourth report of the cooperative open-ended study of slowly growing mycobacteria of the International Working Group on Mycobacterial Taxonomy. Int. J. Syst. Bacteriol. 41:463-472.

33. Wayne, L. G., R. C. Good, A. Tsang, R. Butler, D. Dawson, D. Groothuis, W. Gross, J. Hawkins, J. Kilburn, M. Kubin, K. H. Schroder, V. A. Silcox, C. Smith, M.-F. Thorel, C. Woodley, and M. A. Yakrus. 1993. Serovar determination and molecular taxonomic correlation in Mycobacterium avium, Mycobacterium intracellulare, and Mycobacterium scrofulaceum: a cooperative study of the International Working Group on Mycobacterial Taxonomy. Int. J. Syst. Bacteriol. 43:482-489.

34. Wayne, L. G., E. J. Krichevsky, L. L. Love, R. Johnson, and M. I. Krichevsky. 1980. Taxonomic probability matrix for use with slowly growing mycobacteria. Int. J. Syst. Bacteriol. 30:528-538.

35. Wayne, L. G., and H. A. Sramek. 1991. Agents of newly recognized or infrequently encountered mycobacterial diseases. Clin Microbiol. Rev 5:1-25.

36. Woodley, C. L., M. M. Floyd, and V. A. Silcox. 1992. Evaluation of Syngene DNA-DNA probe assays for the identification of the Mycobacterium tuberculosis complex and the Mycobacterium avium complex. Diagn. Microbiol. Infect. Dis. 15:657-662.

37. Zuckerkandl, E., and L. Pauling. 1965. Molecules as documents of evolutionary history. J. Theor. Biol. 8:357-366. 